This is a self-archived version of an original article. This version may differ from the original in pagination and typographic details.

Author(s): Chernysheva, Maria V.; Bulatova, Margarita; Ding, Xin; Haukka, Matti

Title: Influence of substituents in aromatic ring on the strength of halogen bonding in iodobenzene derivatives

Year: 2020

Version: Accepted version (Final draft)

Copyright: (c) 2020 American Chemical Society

Rights: In Copyright

Rights url: http://rightsstatements.org/page/InC/1.0/?language=en

Please cite the original version:

Chernysheva, M. V., Bulatova, M., Ding, X., \& Haukka, M. (2020). Influence of substituents in aromatic ring on the strength of halogen bonding in iodobenzene derivatives. Crystal Growth and Design, 20(11), 7197-7210. https://doi.org/10.1021/acs.cgd.0c00866 
Subscriber access provided by JYVASKYLAN UNIV

Article

\section{Influence of substituents in aromatic ring on the strength of halogen bonding in iodobenzene derivatives}

Maria V. Chernysheva, Margarita Bulatova, Xin Ding, and Matti Haukka

Cryst. Growth Des., Just Accepted Manuscript • DOI: 10.1021/acs.cgd.0c00866 • Publication Date (Web): 17 Sep 2020

Downloaded from pubs.acs.org on September 20, 2020

\section{Just Accepted}

"Just Accepted" manuscripts have been peer-reviewed and accepted for publication. They are posted online prior to technical editing, formatting for publication and author proofing. The American Chemical Society provides "Just Accepted" as a service to the research community to expedite the dissemination of scientific material as soon as possible after acceptance. "Just Accepted" manuscripts appear in full in PDF format accompanied by an HTML abstract. "Just Accepted" manuscripts have been fully peer reviewed, but should not be considered the official version of record. They are citable by the Digital Object Identifier (DOI®). "Just Accepted" is an optional service offered to authors. Therefore, the "Just Accepted" Web site may not include all articles that will be published in the journal. After a manuscript is technically edited and formatted, it will be removed from the "Just Accepted" Web site and published as an ASAP article. Note that technical editing may introduce minor changes to the manuscript text and/or graphics which could affect content, and all legal disclaimers and ethical guidelines that apply to the journal pertain. ACS cannot be held responsible for errors or consequences arising from the use of information contained in these "Just Accepted" manuscripts. 


\section{Influence of substituents in aromatic ring on the} strength of halogen bonding in iodobenzene derivatives

Maria V. Chernysheva, Margarita Bulatova, Xin Ding, Matti Haukka* Department of Chemistry, University of Jyväskylä, Finland

ABSTRACT: Halogen bonding properties of 3,4,5-triiodobenzoic acid (1, 2), 1,2,3-tribodobenzene (3), 4-iodobenzoic acid (4), pentaiodobenzoic acid ethanol solvate (5), hexaiodobenzene (6a, 6b, 6c), 4-iodobenzonitrile (7), 3-iodobenzonitrile (8), 2,4diiodoaniline (9), 4-iodoaniline (10), 2-iodoaniline (11), 2iodophenol (12), 4-iodophenol (13), 3-iodophenol (14), 2,4,6triiodophenol (15), 4-iodoanisole (16), 3,4,5-triiodoanisole (17) have been studied. The results suggested that substituents other than halogen in the aromatic ring affect XB properties of iodide substituents in ortho-, meta- and para-positions. The effect depends on the electron-withdrawing/electron-donating properties of the substituent. Thus, electron-donating substituents with 
positive mesomeric effect favor m-iodines to act as XB donors. By contrast, electron substituents with negative mesomeric effect favor $0^{-}$and p-iodines to act as XB donors. Furthermore, the stronger the mesomeric effect of the EWG or EDG substituent, the higher impact it makes on the size of the o-hole and, consequently, on the XB donor ability of the iodide substituent.

\section{INTRODUCTION}

Halogen bonding (XB) can be defined as an interaction between Lewis base (electron-density donor, $\mathrm{XB}$ acceptor) and halogen atom (electron-density acceptor, $\mathrm{XB}$ donor). Halogen bonding is acknowledged since 1950th, when Hassel and Hvoslef discovered that Br... bond distances in a crystal structure of Br2/dioxane adduct was shorter than the sum of van der Waals radii of bromine and oxygen, indicating presence of a strong attractive interaction between these atomsi,2. Although, at that time it was called "interaction" or "charge-transfer bonding". The term "halogen bonding" appeared only in 1978 by Dumas and co-workers ${ }^{3}$. Over the years, use of halogen bonding has been developed to a very powerful and useful tool in many chemical fields such as catalysis ${ }^{4-6}$, crystal engineering ${ }^{7-12}$, biochemistry ${ }^{13-15}$, polymer sciences ${ }^{16}$, conductive materials ${ }^{17} 18$, liquid crystals ${ }^{19-21}$ etc. 
Iodine, bromine, chlorine, and rarely fluorine act as XB donors. Polarizability of halogen bond donors increases in the order of $\mathrm{F}$ $<\mathrm{Cl}<\mathrm{Br}<\mathrm{I}^{22}$, making iodine the most favorable XB donor among the halogens 22,23 .

When an atom is involved in a covalent bond, redistribution of electron density takes place, turning the electrostatic potential on this atom to be anisotropic, i.e. electron density decreases along the covalent bond extension and increases in the perpendicular direction to it ${ }^{24}$, as shown in Figure 1. This may lead to the formation of a positive electrostatic potential along the $\mathrm{R}-\mathrm{X}$ bond and increased negative electrostatic potential in a direction, perpendicular to the $\mathrm{R}-\mathrm{X}$ bond. Politzer et. al ${ }^{25}$ have

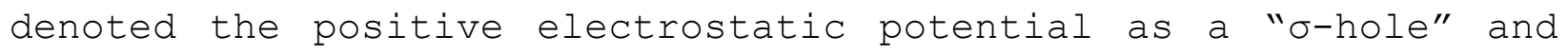
negative electrostatic potential as an "electron belt". Presence of a positive o-hole on the halogen atom explains its ability to interact with nucleophiles in a "head-on" fashion. In turn, a presence of a negative electron belt around the halogen atom allows the interaction of the latter with electrophiles in a "side-on" fashion. Thus, when a halogen $\mathrm{x}$ participates in a halogen bonding via a o-hole, it can be considered as an XB donor (i.e. electron density acceptor). On the other hand, if an interaction takes place via an electron belt, a halogen $\mathrm{X}$ can be considered as an XB acceptor (electron density donor). 


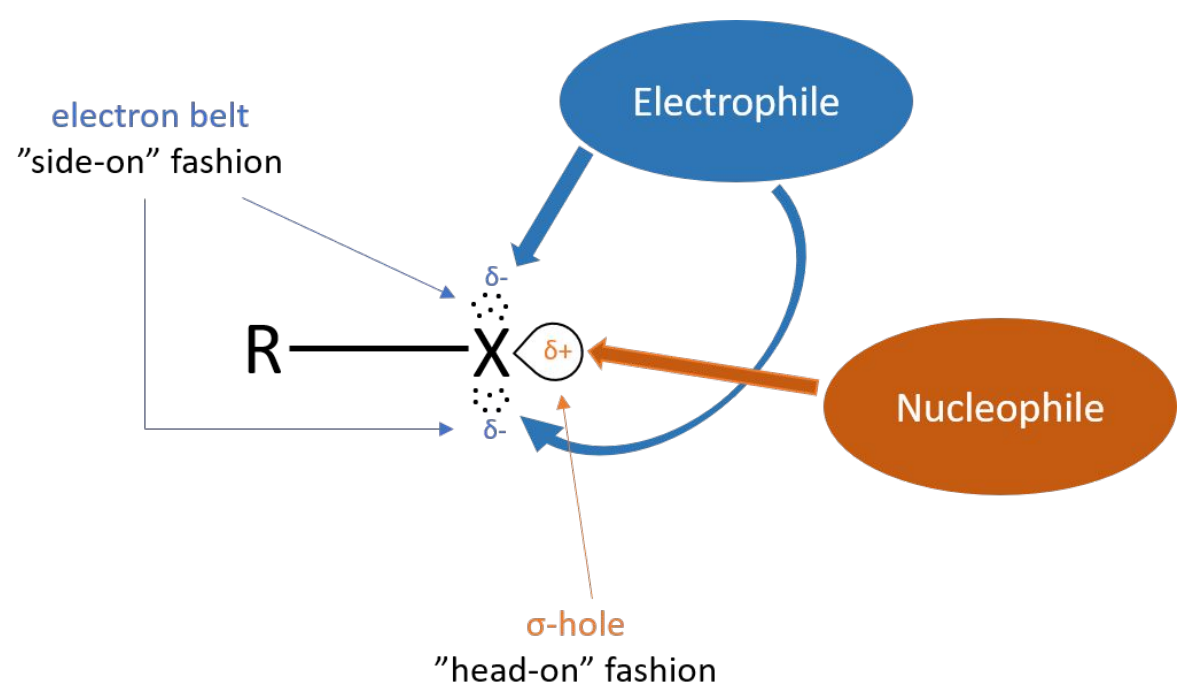

Figure 1. Anisotropic redistribution of the electron density on the atom $\mathrm{X}$, covalently bound to $\mathrm{R}$, where $\mathrm{X}=\mathrm{Hal}, \mathrm{R}=\mathrm{Hal}, \mathrm{C}, \mathrm{N}$, O etc.

Halogen bonding can be classified into two groups depending on the

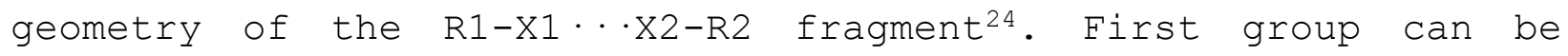

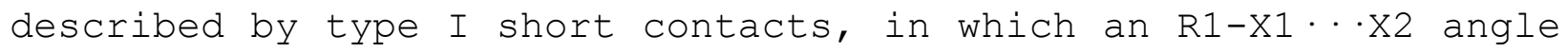

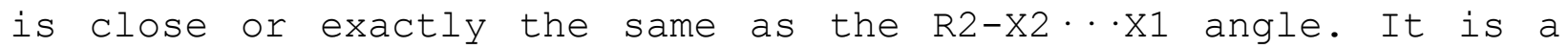
symmetrical interaction and is usually not considered as a true XB, because it typically arises from the close-packing requirements and minimization of repulsion ${ }^{26}$ (Figure 2). Another group of XBs is represented by type II short contacts, in which

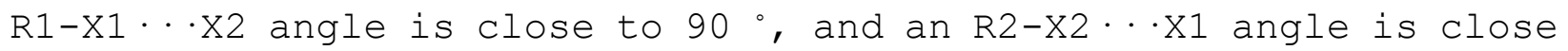
to $180^{\circ}$. This is a bent interaction and is a true XB according to IUPAC definition ${ }^{27}$. 


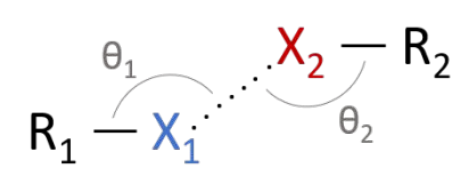

Type I

$\theta_{1} \approx \theta_{2}$

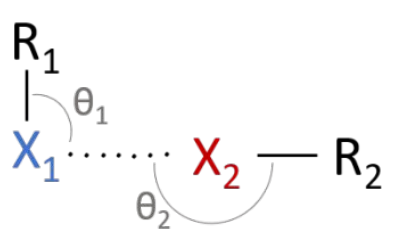

Type II

$\theta_{1} \approx 90^{\circ}$

$\theta_{2} \approx 180^{\circ}$

Figure 2. Types of halogen-halogen contacts.

Halogens attached to hydrocarbons are frequently used for XB investigations as in many cases they can be easily obtained and crystallized ${ }^{28,29}$. In particular, halogenated benzenes are an interesting and convenient class, because halogens can be easily introduced in a benzene ring at different positions. This allows a study of structural features and energies of halogen bonding in a series of related compounds and, to a large extent, an elimination of the side effects like steric constrains etc. Besides this, halobenzenes ${ }^{28,30}$ provide a platform for introducing other types of substituents on the same molecule with possible interactions between the substituents. Investigation of the influence of different substituents with opposite mesomeric effects on the ability of halogens in ortho-, meta- and parapositions to act as XB donor or XB acceptor can contribute to better understanding of halogen bonding. Mesomeric effect can be identified as a redistribution of an electron density in an unsaturated chain due to the conjugation of a polar (electron- 
donating or electron-withdrawing) group with the $\Pi$-system of a molecule. Electron-donating groups revealing a positive mesomeric effect $(+\mathrm{M})$ donate an electron density to a benzene ring. Due to the resonance effect of conjugated double bonds in a benzene ring, the electron density redistributes in a way that higher electron density being localized on carbon atoms in ortho- and parapositions and lower electron density being localized on carbon atoms in meta-positions (Figure 3). In turn, such electron density redistribution could affect the XB donor ability (i.e. an electron density acceptor ability) of halogens, located in ortho-, meta- or para-positions. This may happen because the XB donor ability of halogens increases with the increase of the electron-withdrawing ability of an atom $Y$ bound to halogen atom $X$ :

$$
\mathrm{Y}-\mathrm{X} \cdot \mathrm{A}
$$

where $\mathrm{Y}$ is $\mathrm{C}, \mathrm{N}$, halogen atom etc., $\mathrm{X}$ is the halogen atom (electron density acceptor, XB donor), A is an electron density donor (Lewis base, XB acceptor) (Scheme 1) ${ }^{23}$. Therefore, presence of electrondonating substituents in a benzene ring should favor halogens in meta-positions to act as XB donors. Electron-withdrawing groups, revealing a negative mesomeric effect (-M), on the contrary, lead to the opposite effect with the localization of higher electron density on carbon atoms in meta-positions and lower electron density on carbon atoms in ortho- and para-positions (Figure 3). 
Therefore, halogens in ortho- and para-positions should favor XB donor behavior.
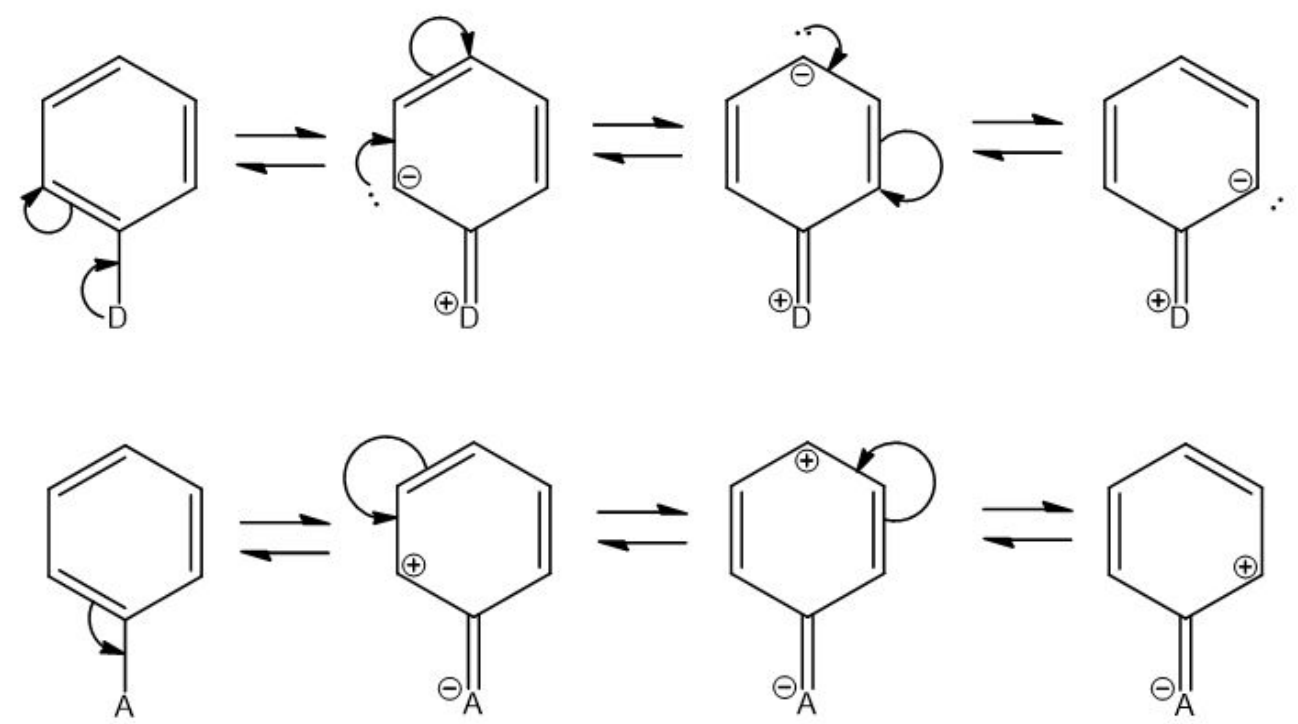

Figure 3. Redistribution of an electron density in a benzene ring by the electron-donor group (D) and the electron-acceptor group (A) •

In the present work, we crystallized and studied the X-ray structures of commercially available 3,4,5-triiodobenzoic acid (1) and 3,4,5-triodobenzoic acid with a solvate (ethanol) molecule (2). Also, we have compared structures of 1 and 2 with the structures of similar substituted iodobenzene derivatives: 1,2,3triiodobenzene (3) ${ }^{31}$, 4-iodobenzoic acid (4) ${ }^{32}$, pentaiodobenzoic acid ethanol solvate (5) ${ }^{33}$, hexaiodobenzene $(\mathbf{6 a}, \mathbf{6 b}, \mathbf{6 c})^{34,35,4-}$ iodobenzonitrile (7) 36, 3-iodobenzonitrile (8) 37, 2,4-diiodoaniline (9) ${ }^{38}$, 4-iodoaniline (10) ${ }^{39}$, 2-iodoaniline (11) ${ }^{40}, \quad$ 2-iodophenol 

(12) $)^{41}$,
4-iodophenol
(13) 37 ,
3-iodophenol
$(14)^{37}$,
$2,4,6-$

triiodophenol (15) ${ }^{42}$, 4-iodoanisole (16) ${ }^{43}, 3$,4,5-triiodoanisole (17) ${ }^{44}$ (Figure 4) found in literature.<smiles>O=C(O)c1cc(I)c(I)c(I)c1</smiles>

1<smiles>Ic1c(I)c(I)c(I)c(I)c1I</smiles>

$6 a, 6 b, 6 c$<smiles>Nc1ccccc1I</smiles>

11<smiles>COc1ccc(I)cc1</smiles>

16<smiles>O=C(O)c1cc(I)c(I)c(I)c1</smiles>

2<smiles>N#Cc1ccc(I)cc1</smiles>

7<smiles>Oc1ccccc1I</smiles>

12<smiles>COc1cc(I)c(I)c(I)c1</smiles>

17<smiles>Ic1cccc(I)c1I</smiles>

3<smiles>N#Cc1cccc(I)c1</smiles>

8<smiles>Oc1ccc(I)cc1</smiles>

13<smiles>O=C(O)c1ccc(I)cc1</smiles>

4<smiles>Nc1ccc(I)cc1I</smiles>

9<smiles>Oc1cccc(I)c1</smiles>

14<smiles>O=C(O)c1c(I)c(I)c(I)c(I)c1I</smiles>

5<smiles>Nc1ccc(I)cc1</smiles>

10<smiles>Oc1c(I)cc(I)cc1I</smiles>

15

Figure 4. Schematic representation of the molecules, chosen for the investigation

In this work we focused especially on the carboxyl-CooH, nitrile $-\mathrm{CN}$, amino $-\mathrm{NH}_{2}$, hydroxy $-\mathrm{OH}$ and methoxy $-\mathrm{OCH}_{3}$ substituents as 
potential halogen bond modifiers on ortho-, meta- and parapositions in relation to the halogen atoms. Iodine was chosen as the XB active atom due to its higher polarizability in comparison with other halogens. This feature makes it easier to study the possible mesomeric effects on its XB properties. The studied systems 1-17 are summarized in Fig 4.

The studied compounds have also many practical applications. Halogenated derivatives of benzoic acids, anilines and phenols can be found in various biological applications ${ }^{45-55}$, pharmacy ${ }^{56}$, biochemistry ${ }^{57-59}$, electrochemistry ${ }^{60}$ catalysis ${ }^{61-67}$ etc. ${ }^{68-72}$. Therefore, the investigation of the XB behavior of this type of molecules may also shed light on details on these processes.

\section{RESULTS AND DISCUSSION}

2.1. Analysis of crystal structures of $\mathbf{1}$ and $\mathbf{2}$

In the structure of $\mathbf{1}$, the I...I distances are in the range of 3.7323 (7) - 3.8791 (7) $\AA$, while the sum of Bondi's van der Waals (vdW) radii is $3.96 \AA^{73}$. Therefore, these interactions are expected to be quite weak. There is also another intermolecular XB between para-iodine of one triiodobenzoic acid (TIBA) molecule and the double bonded oxygen atom 01 of a carboxyl group of another TIBA molecule $(\mathrm{I} \cdots \mathrm{O}=\mathrm{C}=3.031$ (6) -3.138 (5) $\AA$, Figure 5). This interaction is already somewhat stronger based on the donor- 
acceptor distance (sum of vdW radii is $3.5 \AA$ ). It should be noted that meta-iodines participate in a halogen bonding both as XB donors and XB acceptors, while para-iodines act only as XB donors and interact only with the double bonded oxygen atom of the neighboring molecule.

The I atoms in meta-position relative to the - COOH substituent (II and I3) adopt different types of XB geometries. I1 is bound to two I3B of two adjacent molecules providing a non-linear C4-I1 $\cdots$ I3BC6B fragment with the $\mathrm{C}-\mathrm{I} \cdot \mathrm{I}$ I angles close to $90^{\circ}(\mathrm{C} 4-\mathrm{I} 1 \cdots \mathrm{I} 3 \mathrm{~B}=$ 99.4 (2) and $\mathrm{C} 6 \mathrm{~B}-\mathrm{I} 3 \mathrm{~B} \cdots \mathrm{I} 1=88.9$ (2) ${ }^{\circ}$ ) and close to $180^{\circ}$ (C6B$\mathrm{I} 3 \mathrm{~B} \cdots \mathrm{II}=158.8$ (2) and $\mathrm{C} 4-\mathrm{I} 1 \cdots \mathrm{I} 3 \mathrm{~B}=169.2$ (2) $\left.{ }^{\circ}\right)$. Therefore, this contact can be considered as type II XB (Figure 5), in which one angle in the $\mathrm{R}-\mathrm{X} \cdot \mathrm{X}-\mathrm{X}$ fragment is close to $90^{\circ}$ and another angle is close to $180^{\circ}$. 


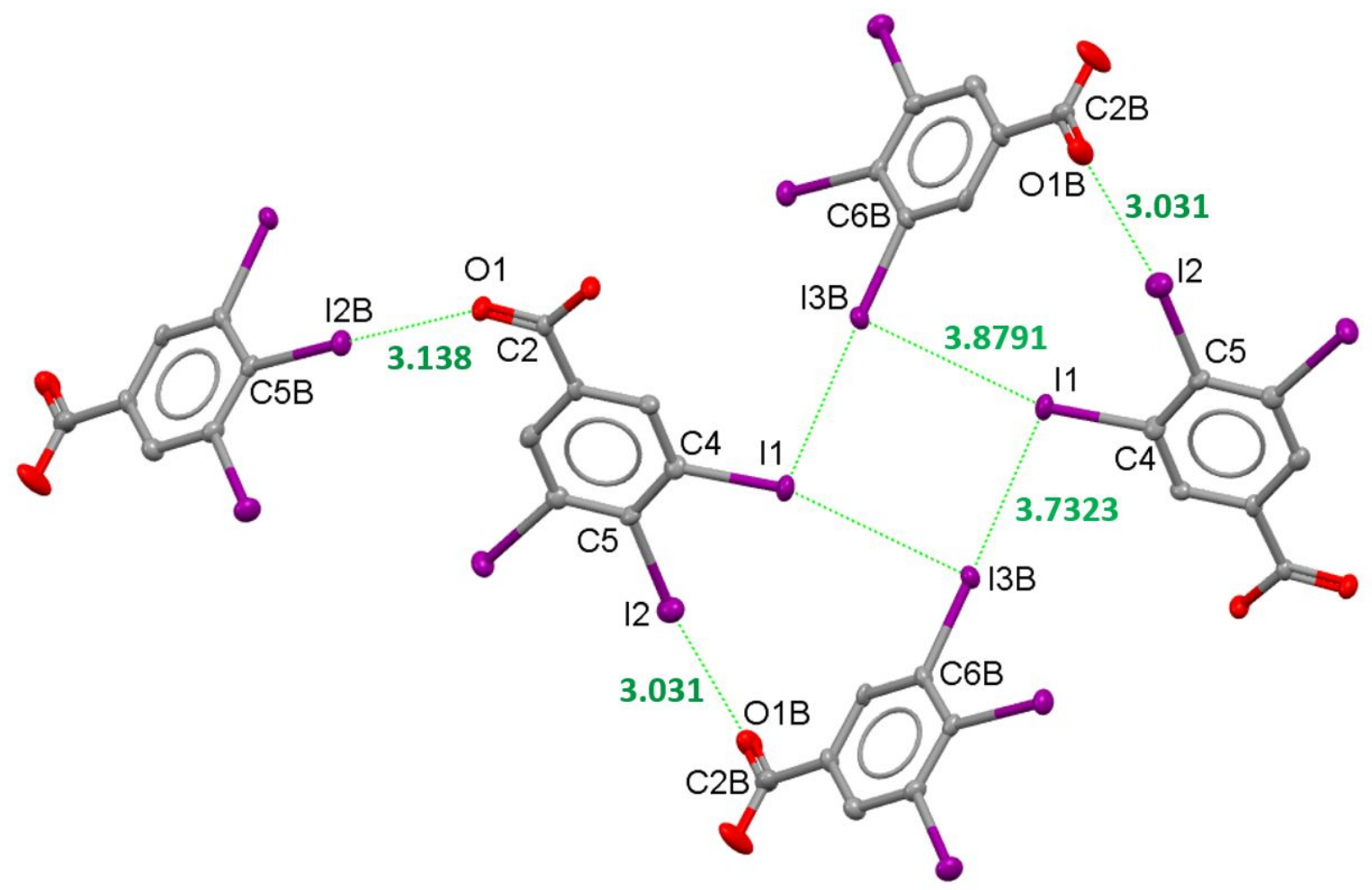

Figure 5. Halogen bonds in 1. Type II contacts. Hydrogens are omitted for clarity. Selected bond lengths ( $)$ and angles ( $\left.{ }^{\circ}\right)$ : I1$\mathrm{I3B}{ }^{(i)} 3.8791$ (7), I1-I3B(i) 3.7323 (7), I2B-O13.138 (5), I2-O1B(i) 3.031 (6), C4-I1-I3B(i) 99.4 (2), C4-I1-I3B(i) 158.8 (2), $\mathrm{C}^{\left(\mathrm{i} \mathrm{B}^{(i)}-\right.}$ $I 3 B^{(i)}-I 188.9$ (2), $C 6 B^{(i)}-I 3 B^{(i)}-I 1169.2 \quad$ (2), $C 5-I 2-O 1 B^{(i)} 171.5$ (2), $\mathrm{C} 2 \mathrm{~B}^{(\mathrm{i})}-\mathrm{O} 1 \mathrm{~B}^{(\mathrm{i})}-\mathrm{I} 2111.3(5), \mathrm{C} 5 \mathrm{~B}-\mathrm{I} 2 \mathrm{~B}-\mathrm{O} 1178.8$ (2), $\mathrm{C} 2-\mathrm{O} 1-\mathrm{I} 2 \mathrm{~B}$ 143.8 (5). Equivalent positions: (i) $x,-1+y, z$. In contrast, the I1B (Figure 6) is connected to the I1B of the adjacent molecule in such a way that the C4B-I1B $\cdots I 1 B-C 4 B$ fragment is almost linear with equal angles $(\mathrm{C} 4 \mathrm{~B}-\mathrm{I} 1 \mathrm{~B} \cdots \mathrm{I} 1 \mathrm{~B}=\mathrm{I} 1 \mathrm{~B} \cdots \mathrm{I} 1 \mathrm{~B}-\mathrm{C} 4 \mathrm{~B}$ $=152.3(2)^{\circ}, I 1 B \cdots I 1 B=3.7598$ (6) $\left.\AA\right)$. Therefore, this contact is an example of a type I halogen bonding (Figure 6). Despite type 
I XB is quite typical for $\mathrm{Cl}$ and $\mathrm{Br}$, only few compounds are known in which structures $I$ is involved in this type of interactions ${ }^{24}$. Therefore, 1 is a rare example of the substances of this class.

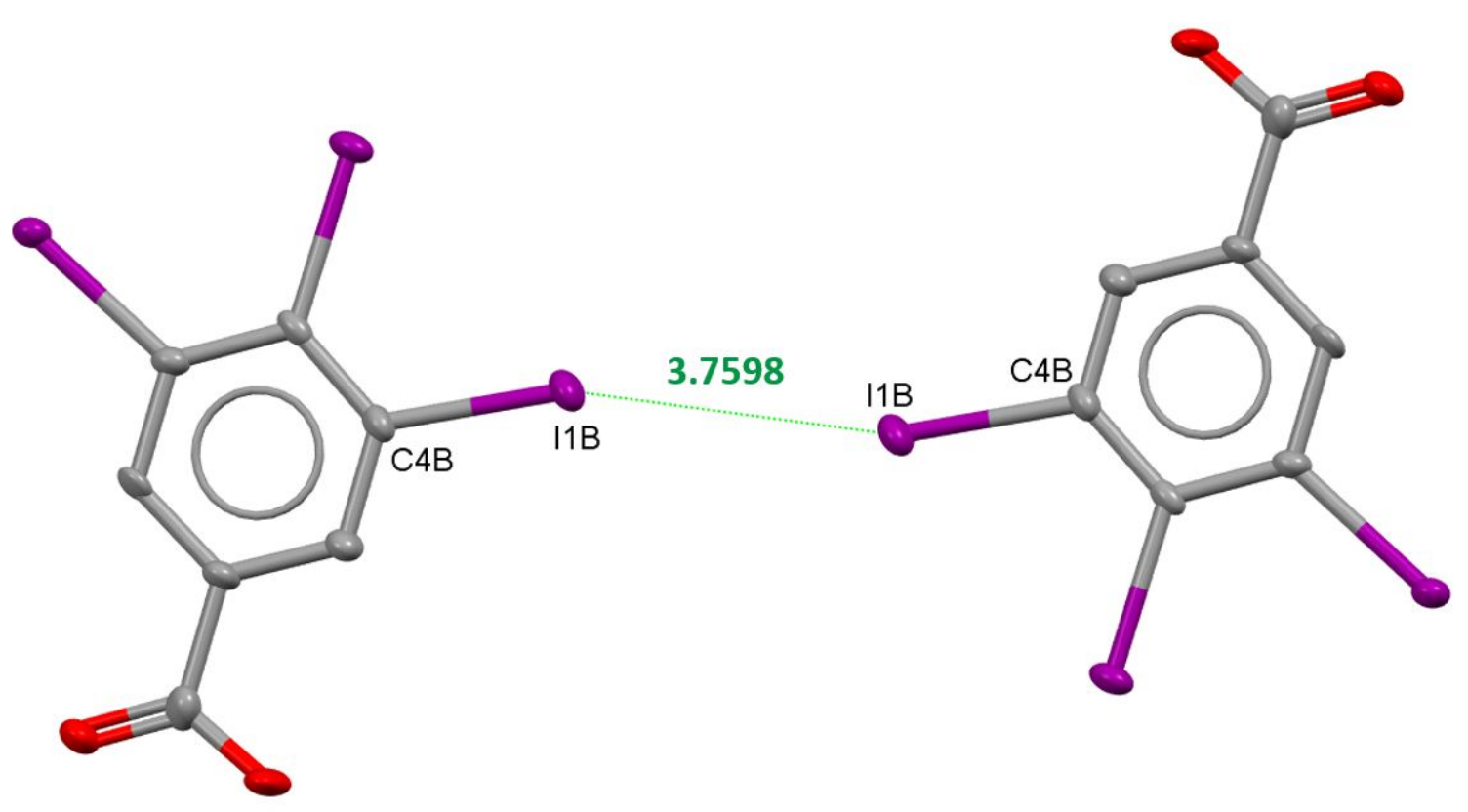

Figure 6. Halogen bonds in 1. Type I contacts. Hydrogens are omitted for clarity. Selected bond lengths ( $⿱$ A) and angles $\left({ }^{\circ}\right)$ : I1B$I 1 B^{(i)} 3.7598$ (6), $C 4 B-I 1 B-I 1 B^{(i)} 151.3$ (2), $C^{(1)} B^{(i)}-I 1 B^{(i)}-I 1151.3$ (2). Equivalent positions: (i) 1-x, 1-y, 1-z.

Hydrogen bonding (Table 1 ) between two carboxyl groups is rather strong in the structure of 1 being $1.806 \AA$ and $1.811 \AA$ (sum of vdW radii of $\mathrm{H}$ and $\mathrm{O}$ is $2.62 \AA)$. It clearly shows that the $\mathrm{HB}$ is the key structural factor in this structure (see Figure S1).

Each molecule of 1 is bound to two adjacent molecules by $\Pi-\Pi$ interactions with the corresponding distance between the 
calculated centroids of benzene rings $4.300 \AA$. Such stacking together with other described non-covalent interactions lead to a zig-zag packing of the molecules (Figure 7).

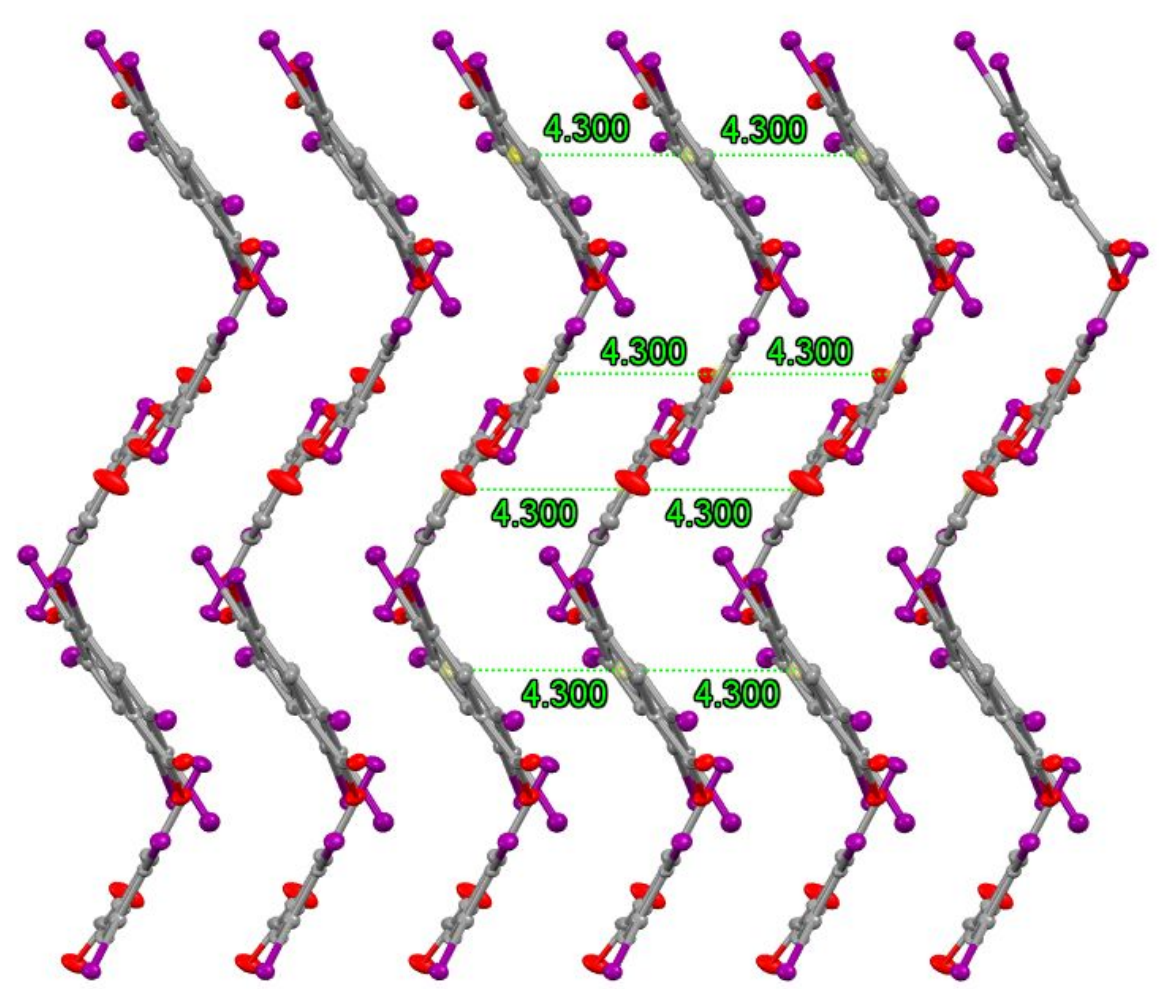

Figure 7. Zig-zag layers of 1. Hydrogens are omitted for clarity. Distance is measured between the calculated centroids of benzene rings.

The presence of a solvent molecule in the structure of $\mathbf{2}$ changes drastically the whole arrangement of molecules as well as their interaction modes (Figures 8 and 9). Thus, the I $\cdots I$ distance is 3.7851 (8) and 3.8165 (9) $\AA$ for meta- and para-iodines, correspondingly, which is relatively close to I...I distance in 1 
and is again less than the sum of vdW radii (3.96 $\AA)^{73}$. However, in 2 there are no type I contacts. Instead, all iodines interact with iodines of the adjacent molecules via type II contacts. Iodine atoms in meta-position relative to the - $\mathrm{COOH}$ substituent (I1 and I3) show different XB behavior than the corresponding atoms in 1 (Figure 8). I1 is bound to I3 of an adjacent molecule providing

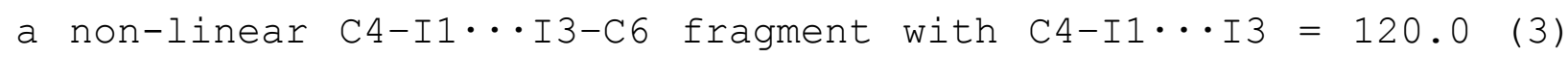

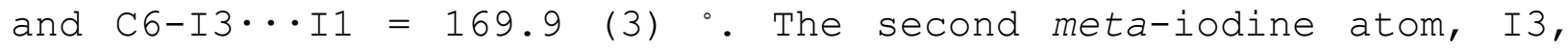
forms XBs with two adjacent molecules giving a C6-I3-..I1-C4

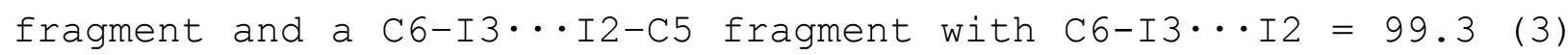
and $\mathrm{C} 5-\mathrm{I} 2 \cdots \mathrm{I3}=169.8$ (2) ${ }^{\circ}$. Thus, I1 behaves as an XB acceptor and I3 shows both XB donor and XB acceptor properties. The paraiodine I2 participates in a halogen bonding with one adjacent molecule and behaves as an XB donor, resulting in a close to linear

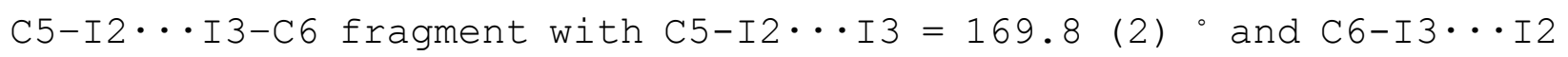
$=99.3(3)^{\circ}$. 


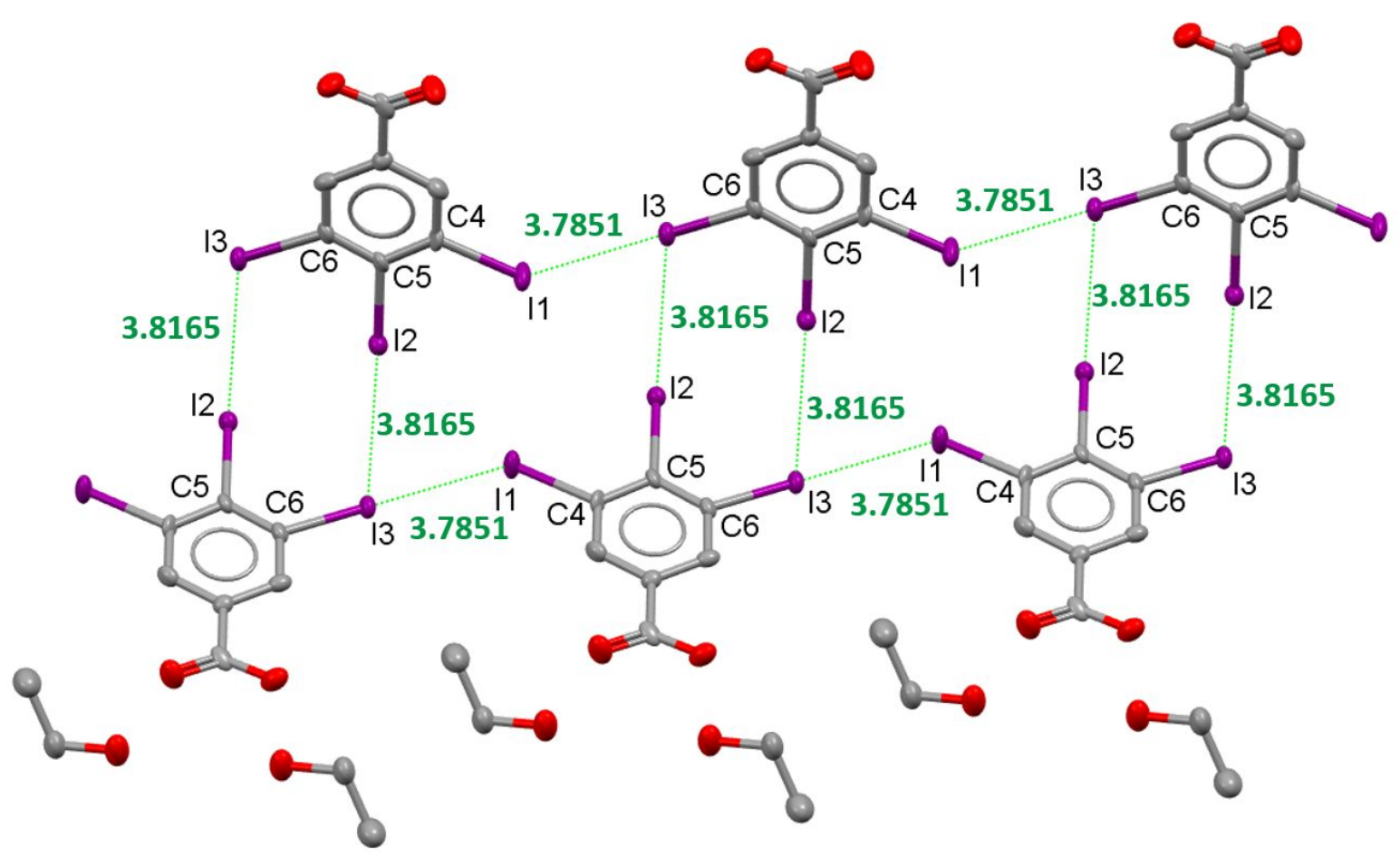

Figure 8. Structure of 2. Hydrogens are omitted for clarity. Selected bond lengths ( $\AA$ ) and angles $\left({ }^{\circ}\right)$ : I1-I3(i) 3.7851 (8), I2I3(ii) 3.8165 (9), C4-I1-I3 (i) 120.0 (3), C6 (i) $-I 3^{(i)}-I 1169.9$ (3), C5-I2-I3(ii) 169.8 (2), C6(ii)-I3(ii)-I2 99.3 (3). Equivalent positions: (i) $1 / 2+x,-1 / 2+y, z$; (ii) $1 / 2-x, 1 / 2+y, 1 / 2-z$.

In 2, ethanol molecules form strong hydrogen bonds (Table 1) with

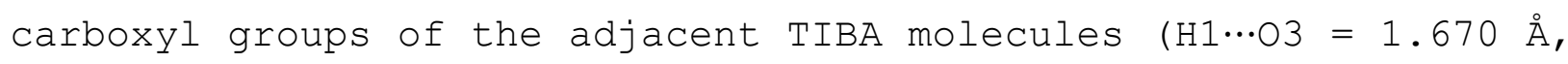
H3A $\cdots O 2=1.862 \AA)$. The $\mathrm{H} \cdots \mathrm{O}$ distance is again much shorter than the sum of vdW radii (2.62 $⿱$ ) . This indicates that HB plays a central role also in the crystal structure of 2 (see Figures2). 
Table 1. Hydrogen bond parameters in $\mathbf{1}$ and $\mathbf{2}$.

\begin{tabular}{|c|c|c|c|c|c|c|c|}
\hline & $\mathrm{D}-\mathrm{H}$ & $\begin{array}{c}d(D- \\
H)\end{array}$ & $d(H \ldots A)$ & $<D H A$ & $d(D . . A)$ & $\mathbf{A}$ & $\begin{array}{l}\text { Equivalent } \\
\text { positions } \\
\text { of (i-iii) }\end{array}$ \\
\hline \multirow[t]{3}{*}{1} & $\mathrm{O} 2-\mathrm{H} 2$ & 0.840 & 1.811 & 177.8 & $\begin{array}{c}2.650 \\
(7)\end{array}$ & $\mathrm{O} 1^{(\mathrm{i})}$ & $\begin{array}{c}2-x, \quad 1-y \\
-z\end{array}$ \\
\hline & $\mathrm{C} 7-\mathrm{H} 7$ & 0.950 & 3.0558 & 160.9 & $\begin{array}{c}3.966 \\
(8)\end{array}$ & I2 & \\
\hline & $\mathrm{O} 2 \mathrm{~B}-\mathrm{H} 2 \mathrm{~B}$ & 0.841 & 1.806 & 165.0 & $\begin{array}{c}2.63 \\
(1)\end{array}$ & O1B ${ }^{\text {(ii) }}$ & $\begin{array}{c}-1-x, 2-y, \\
1-z\end{array}$ \\
\hline \multirow[t]{2}{*}{2} & $\mathrm{O} 1-\mathrm{H} 1$ & 0.884 & 1.670 & 171.3 & $\begin{array}{c}2.55 \\
(1)\end{array}$ & O3(iii) & $\begin{array}{c}1-x,-y, \\
1-z\end{array}$ \\
\hline & O3-H3A & 0.939 & 1.862 & 145.7 & $\begin{array}{c}2.69 \\
(1)\end{array}$ & $\mathrm{O} 2$ & \\
\hline
\end{tabular}

The incorporation of the ethanol molecule into the crystal structure of 3,4,5-triiodobenzoic acid does not break the $\Pi-\Pi$ stacking of the aromatic rings, although the distance between them is slightly longer than in the case of 1 (distance between the calculated centroids of benzene rings is $4.470 \AA$ ). Like in 1 , the molecules of 2 are organized in a zig-zag layout (Figure 9). 


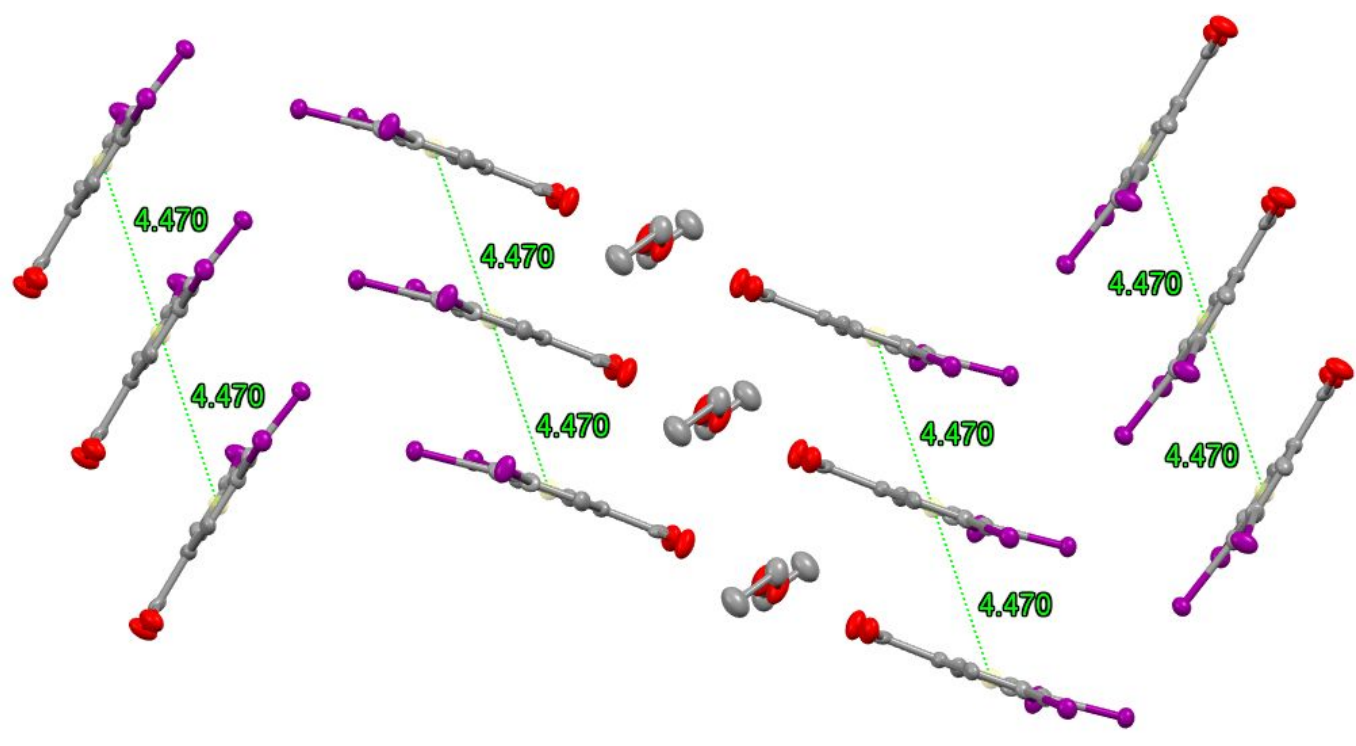

Figure 9. Layers of 2. Hydrogens are omitted for clarity. Distance is measured between the calculated centroids of benzene rings.

In addition to the intermolecular halogen bonding, there is also an intramolecular XB present in the structures of $\mathbf{1}$ and $\mathbf{2}$ with the

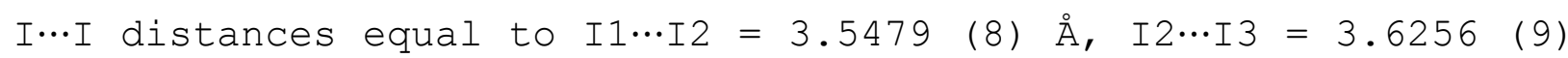
$\AA, I 1 B \cdots I 2 B=3.6045$ (7) $\AA, I 2 B \cdots I 3 B=3.6464$ (6) $\AA$ for 1 and I1 $\cdots I 2$ $=3.6126$ (8) $\AA$ and $I 2 \cdots I 3=3.620$ (1) $\AA$ for 2 .

2.2. Influence of the substituent on the XB behavior of halogens in substituted iodobenzenes

A carboxyl group present in TIBA is a substituent with -M effect. Therefore, it is expected to decrease the electron density on the carbon atoms in ortho- and para-positions of the ring and to increase the electron density on the carbon atom in meta-position. Because of this phenomenon, in 1 and 2 C5, located in para-position 
relative to $-\mathrm{COOH}$, should withdraw some electron density from the I2 bound to it. An opposite effect should be observed for I1 and I3 in meta-positions. As a result, I2 should become a better XB donor, while I1 and I3 should become better XB acceptors. Such phenomenon was indeed observed in the structures of $\mathbf{1}$ and 2 . Thus, analysis of the crystal structure of 1 showed that para-iodines I2 and I2B are involved in a stronger halogen bonding with oxygen of the carboxyl group $\left(\mathrm{C} 5-\mathrm{I} 2 \cdots \mathrm{O} 1 \mathrm{~B}=171.5\right.$ (2) ${ }^{\circ}$ and $\mathrm{I} 2 \cdots \mathrm{O} 1 \mathrm{~B}=3.031$ (6) $\AA, \mathrm{C} 5 \mathrm{~B}-\mathrm{I} 2 \mathrm{~B} \cdots \mathrm{O} 1=178.8$ (2) ${ }^{\circ}$ and $\mathrm{I} 2 \mathrm{~B} \cdots \mathrm{O} 1=3.138$ (5) $\AA$ ) as well as interact with the $\Pi$-system of the neighboring benzene ring Both these facts indicate an improved XB donor (i.e. an electron acceptor) behavior of para-iodines. Meta-iodines I1 and I3B, in

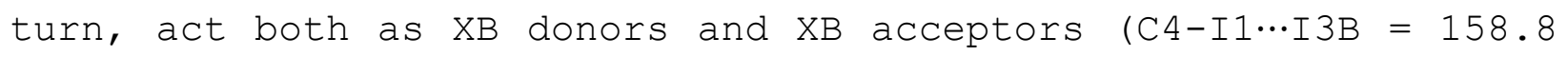

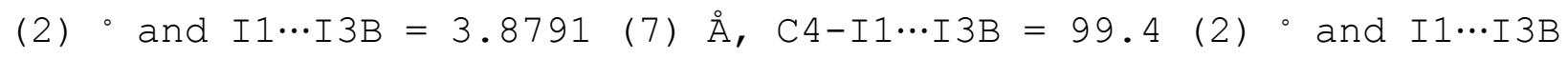
$=3.7323(7) \AA, C 6 B-I 3 B \cdots I 1=169.2$ (2) ${ }^{\circ}$ and $I 3 B \cdots I 1=3.7323$ (7) $\AA, C 6 B-I 3 B \cdots I 1=88.9$ (2) ${ }^{\circ}$ and $I 3 B \cdots I 1=3.8791$ (7) $\AA$ ) .

Analysis of the structure of 2, which contains co-crystallized ethanol, showed even more clear distinction between para-iodines I1 and I3 and meta-iodines I2. Former ones act only as XB donors

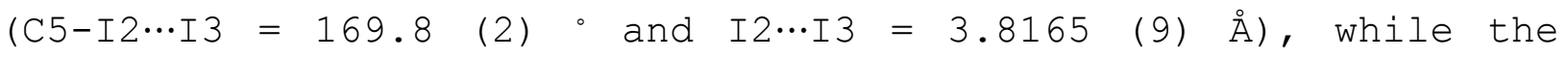
latter ones favor XB acceptor behavior $\left(C 4-I 1 \cdots I 3=120.0\right.$ (3) ${ }^{\circ}$ and

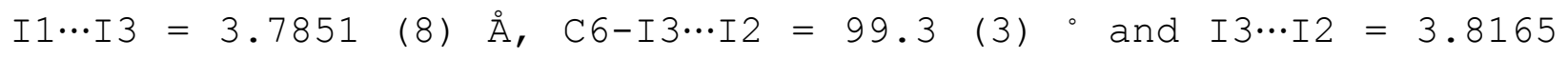
(9) $\AA, C 6-I 3 \cdots I 1=169.9$ (3) ${ }^{\circ}$ and $I 3 \cdots I 1=3.7851$ (8) $\AA$ ). ACS Paragon Plús Environment 
In order to characterize a o-hole on each halogen atom, the calculated electrostatic potentials can be used. The maximum electrostatic potential on the atom can be represented by a value of $V_{S, \max }$, which is proportional to the size of a $\sigma$-hole. The bigger the o-hole on the atom, the bigger is the $V_{S}$, max value. In turn, a bigger size of a $\sigma$-hole (and bigger $V_{\mathrm{S} \text {, max }}$ value) corresponds to a higher XB donor ability of halogen. Our calculations show that $V_{\mathrm{S}, \max }$ values for I1, I2 and I3 in compounds 1 and $\mathbf{2}$ vary from 0.039 to 0.042, being smallest for meta-iodines I1 and I3 and biggest for para-iodines I2 (see section 2.3). Therefore, iodine atoms in para-position should reveal better XB donor ability than iodines in meta-positions, which is which is consistent with the results of our structural analysis.

Table 2. Halogen bonding in $\mathbf{1}$ and 2 .

\begin{tabular}{|c|c|c|c|c|c|}
\hline & Atoms & $\begin{array}{c}\text { Distance, } \\
\AA\end{array}$ & Angles, & $\begin{array}{c}\text { Sum of } \\
\text { vdw } \\
\text { radii, } \AA\end{array}$ & $\begin{array}{l}\text { Equivalent } \\
\text { positions } \\
\text { of (i)- } \\
\text { (iii) }\end{array}$ \\
\hline 1 & I2 $\cdots$ O1B & $3.138 \quad(5)$ & $\begin{array}{l}C 5-I 2-O 1 B= \\
178.8 \quad(2), \\
C 2 B-O 1 B-I 2= \\
143.8 \quad(5)\end{array}$ & 3.5 & \\
\hline
\end{tabular}




\begin{tabular}{|c|c|c|c|c|c|}
\hline & I1 $\cdots$ I3B $^{(i)}$ & $\begin{array}{c}3.7323 \\
(7)\end{array}$ & $\begin{array}{l}C 4-I 1-I 3 B^{(i)}= \\
99.4 \quad(2), \\
C 6 B^{(i)}-I 3 B^{(i)}- \\
I 1=169.2 \\
(2)\end{array}$ & 3.96 & $x, \quad-1+y, \quad z$ \\
\hline & I3B(i) $\cdots$ I1 & $\begin{array}{c}3.8791 \\
(7)\end{array}$ & $\begin{array}{l}C 6 B^{(i)}-I 3 B^{(i)}- \\
I 1=88.9 \\
(2), C 4-I 1- \\
I 3 B^{(i)}=158.8 \\
(2)\end{array}$ & 3.96 & $x,-1+y, \quad z$ \\
\hline 2 & I1 $\cdots$ I3 $^{(\text {ii) }}$ & $\begin{array}{c}3.7851 \\
(8)\end{array}$ & $\begin{array}{l}C 4-I 1-I 3^{(i i)}= \\
120.0(3), \\
C 6^{(i i)}-I 3^{(i i)}-I 1 \\
=169.9\end{array}$ & 3.96 & $\begin{array}{l}1 / 2+x, \quad- \\
1 / 2+y, \quad z\end{array}$ \\
\hline & I2 $\cdots$ I3 $^{\text {(iii) }}$ & $\begin{array}{c}3.8165 \\
(9)\end{array}$ & $\begin{array}{l}\mathrm{C} 5-\mathrm{I} 2-\mathrm{I} 3^{(\mathrm{iii})}= \\
169.8(2), \\
\mathrm{C} 6^{(\mathrm{iii})}-\mathrm{I} 3^{(\mathrm{iii})}- \\
\mathrm{I} 2=99.3\end{array}$ & 3.96 & $\begin{array}{l}1 / 2-x, \\
1 / 2+y \\
1 / 2-z\end{array}$ \\
\hline
\end{tabular}

In contrast, the removal of a -COOH substituent should equalize, to a large extent, the XB properties of all the I atoms. This is reflected in our calculations, according to which, $V_{S}$, max values are 
0.036 and are same for all iodines. However, the structural analysis of 1,2,3-triiodobenzene ${ }^{31}$ molecule 3 (Figure 10) shows, that two outermost iodines, I3 and I4, act as XB donors (C3-I3 $\cdots I 6$

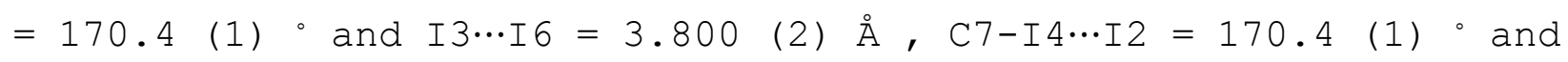
I4‥I2 = 3.802 (2) $\AA$ ), while another outermost iodine atom, I6,

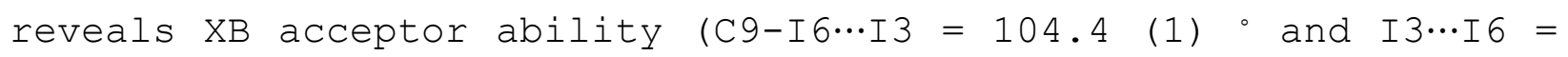
3.800 (2) $\AA$ ). The middle iodine atom, I2, also favors the XB

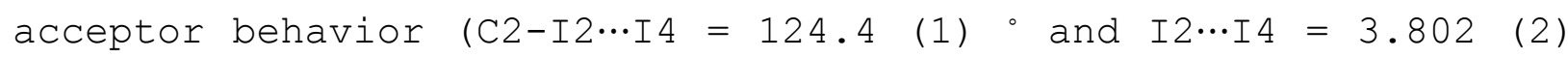
$\AA)$. Such difference in the XB donor-acceptor behavior of iodide substituents is due to the weak positive mesomeric effect of the neighboring iodine atoms.

It should be noted, that molecules in 3 do not form infinite chains of halogen bonds, like in $\mathbf{1}$ and $\mathbf{2}$, but make two sets of four molecules (Figure S3). Only two iodines in one molecule form halogen bonds, while third iodine is not involved, i.e. in one molecule I2 and I3 form XBs and I1 does not. In the second molecule I4 and I6 form XBs, while I5 does not. 


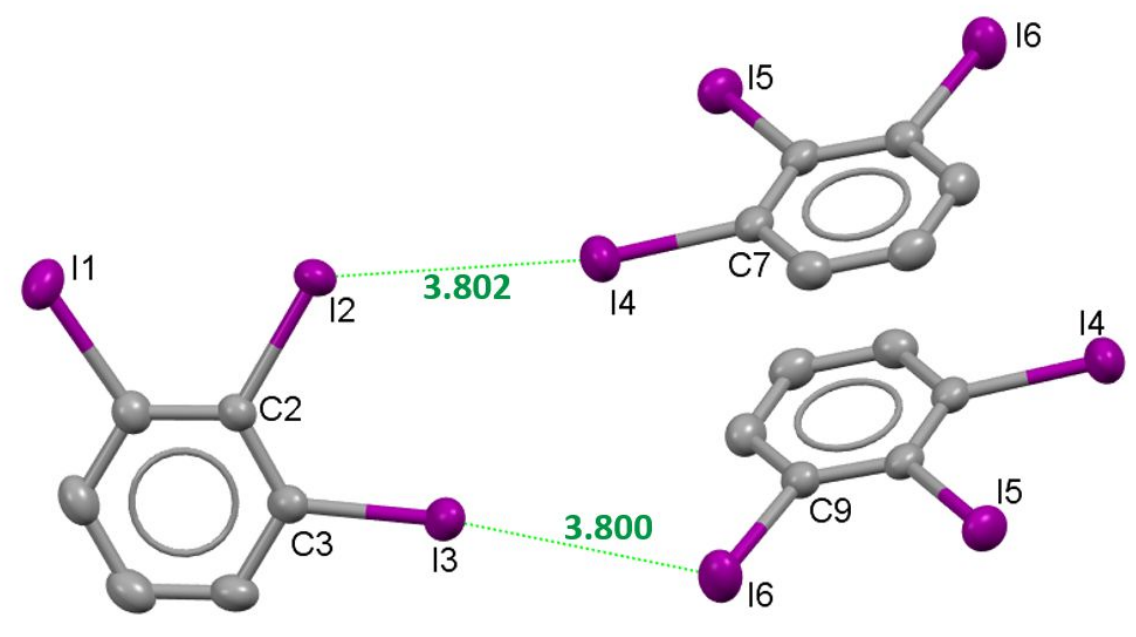

Figure 10. Structure of 3. Hydrogens are omitted for clarity. Selected bond lengths $(\AA)$ and angles $\left({ }^{\circ}\right)$ : I4 ${ }^{(i)}-I 23.802$ (2), I6 (ii) I3 3.800 (2), C2-I2-I4(i) 124.4 (1), C7(i)-I4(i)-I2 170.4 (1), C3I3-I6 (ii) 170.4 (1), C9(ii)-I6(ii) $-I 3104.4$ (1). Equivalent positions: (i) $x, 1+y, z$; (ii) 2-x, 2-y, 1-z.

Table 3. Halogen bonds in 3 .

\begin{tabular}{|c|c|c|c|c|c|}
\hline & Atoms & $\begin{array}{c}\text { Distance, } \\
\AA\end{array}$ & Angles, & $\begin{array}{c}\text { Sum of } \\
\text { vdW } \\
\text { radi } i, \AA\end{array}$ & $\begin{array}{l}\text { Equivalent } \\
\text { positions } \\
\text { of (i)-(ii) }\end{array}$ \\
\hline 3 & $I 2 \cdots I 4^{(i)}$ & $3.802 \quad(2)$ & $\begin{array}{l}C 2-I 2-I 4^{(i)}= \\
124.4 \quad(1), \\
C 7^{(i)}-I 4^{(i)}-I 2= \\
170.4 \quad(1)\end{array}$ & 3.96 & $x, 1+y, z$ \\
\hline
\end{tabular}




\begin{tabular}{|c|c|c|c|c|}
\hline I3 $\cdots$ I6 ${ }^{(i i)}$ & $3.800 \quad(2)$ & $\begin{array}{l}C 3-I 3-I 6^{(i i)}= \\
170.4 \quad(1), \\
C 9^{(i i)}-I 6^{(i i)}-I 3 \\
=104.4(1)\end{array}$ & 3.96 & $\begin{array}{c}2-x, 2-y, \\
1-z\end{array}$ \\
\hline
\end{tabular}

Similar mesomeric effects can be observed in other iodobenzoic acids as well. For example, in 4-iodobenzoic acid (4) ${ }^{32}$ the iodine atom in a para-position should act as an XB donor because of the -M effect of a carboxyl group. According to our structural analysis, the iodine atom I1 interacts with other I1 iodine atoms from two adjacent molecules, acting both as an XB donor and as an $\mathrm{XB}$ acceptor (Figure 11). The corresponding I...I distance is 3.957 (1) $\AA$, which is very close to the sum of vdW radii, so both I1‥II interactions can, thus, be considered as extremely weak ones. The calculated $V_{\mathrm{S} \text {,max }}$ value is 0.035 . 


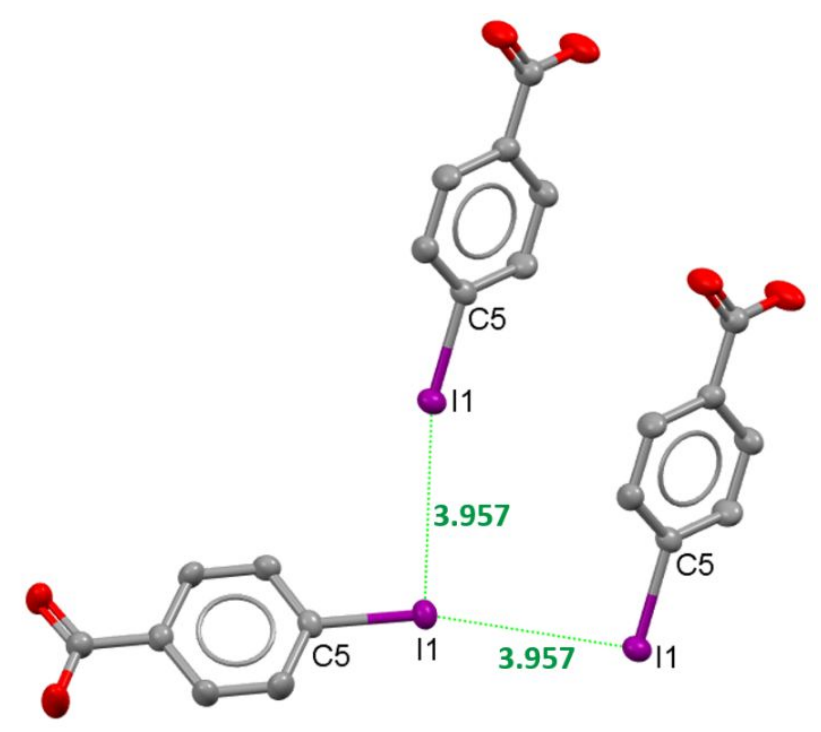

Figure 11. Structure of 4. Hydrogens are omitted for clarity. Selected bond lengths $(\AA)$ and angles $\left({ }^{\circ}\right)$ : I1-II(i) 3.957 (1), I1$I 1^{(i i)} 3.957$ (1), C5-I1-I1 (i) 165.9 (2), C5 (i) $-I 1^{(i)}-I 196.1$ (2), C5I1-I1(ii) 96.1 (2), C5 (ii)-I1 (ii)-I1 165.9 (2). Equivalent positions: (i) $1 / 2-x, 1 / 2+y, 1 / 2-z ;$ (ii) 1/2-x, -1/2+y, 1/2-z .

Adonin et al. have reported ${ }^{33}$ the synthesis of another iodobenzoic acid, i.e. pentaiodobenzoic acid (PIBA). In PIBA the electron density distribution is affected by the negative mesomeric effect of a - $\mathrm{COOH}$ group, which withdraws the electron density from the benzene ring. Thus, ortho- and para-iodines should act as XB donors, while iodines in meta-positions should accumulate excessive electron density favoring corresponding iodines to act as XB acceptors. Analysis of the crystal structure of pentaiodobenzoic acid (5) revealed that the carboxyl group is not coplanar with the benzene ring because of the steric hindrance as 
well as due to the strong hydrogen bonding between two carboxyl groups in adjacent molecules (Figure 12). Therefore, conjugation breaks down, and $-\mathrm{COOH}$ group does not influence the $\mathrm{XB}$ donoracceptor properties of iodines. This is also confirmed by our computations, showing a small deviation of a o-hole for all iodines. The calculated $V_{S, \max }$ is 0.050 for ortho-iodines and 0.047 for meta- and para-iodines (see section 2.3). The difference in $V_{S, \max }$ values is due to the $+\mathrm{M}$ effect of the iodines.

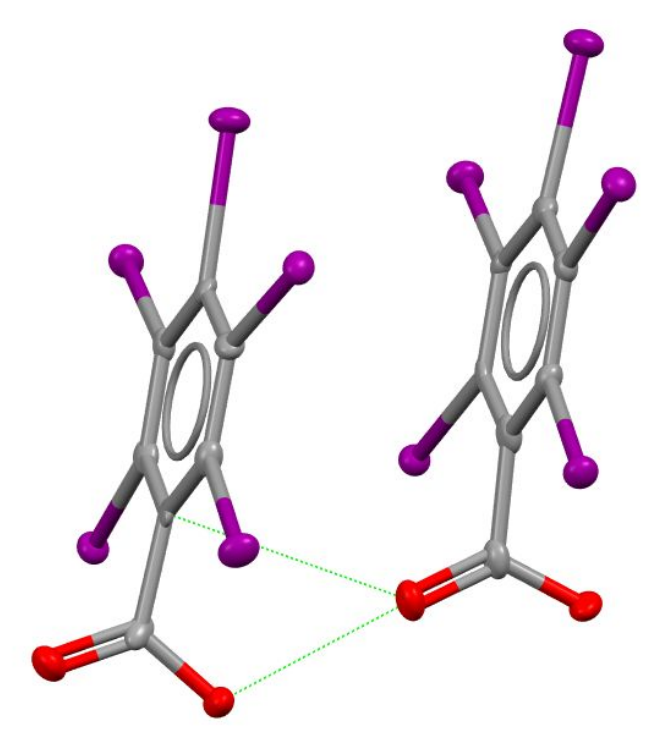

Figure 12. Structure of 5. Hydrogens and solvent molecules were omitted for clarity.

In a PIBA structure (Table 4), meta-iodines I2 and I4 form XBs with adjacent molecules with I2 acting as an XB donor (C6-I2 $\cdots I 4=$

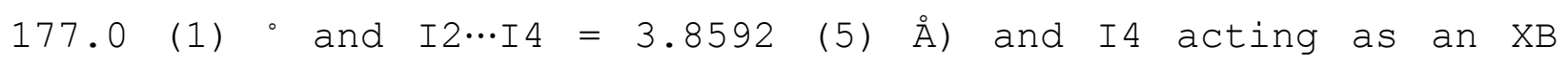

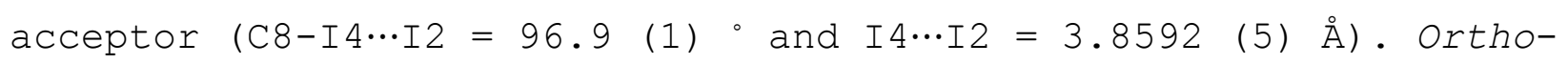


iodines I5 and I6 form even stronger XBs with oxygens from the carboxyl group 06 and 02 , correspondingly, thus, acting as XB

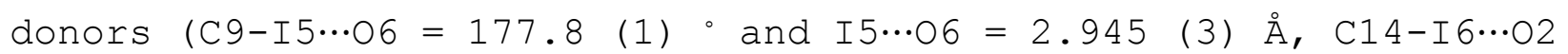
$=170.6(1){ }^{\circ}$ and $I 6 \cdots 02=3.092$ (3) $\AA$ ). This can be explained by a small positive mesomeric effect of the substituted iodines, that favors meta-positions to act as XB donors and ortho-positions as XB acceptors. Finally, para-iodines I3 and I8 form type I contacts with ortho- and para-iodines from the adjacent molecule (C7-I3 $\cdots$ I9

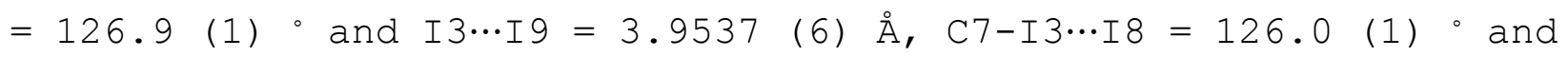

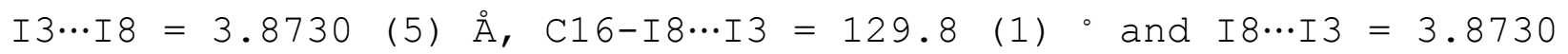
(5) $\AA$ ).

Table 4. Halogen bonds in 5 .

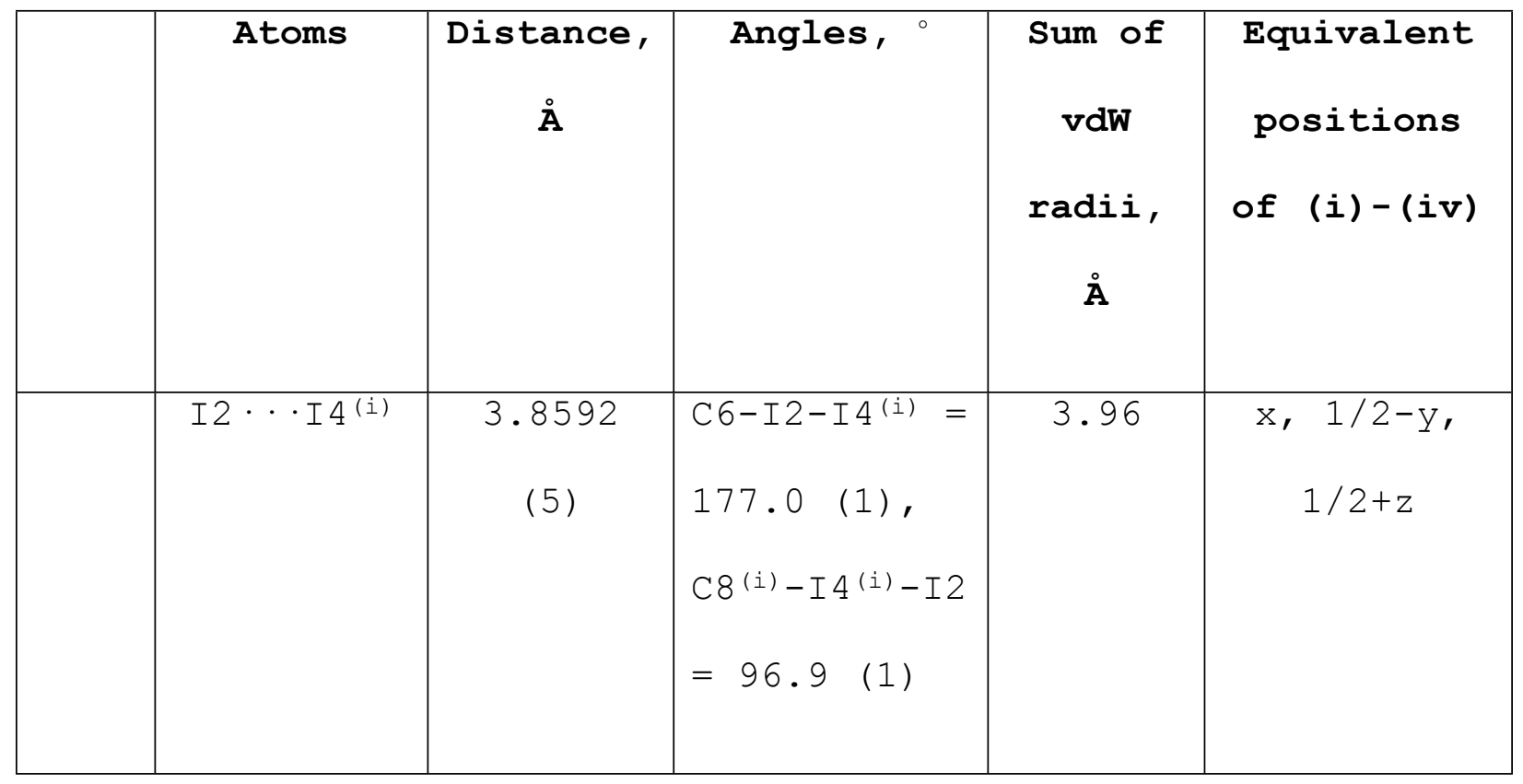




\begin{tabular}{|c|c|c|c|c|c|}
\hline 5 & I3 $\cdots$ I $^{\text {(ii) }}$ & $\begin{array}{c}3.8730 \\
(5)\end{array}$ & 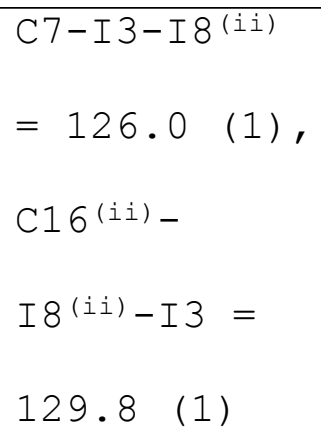 & 3.96 & $\begin{array}{c}-x,-1 / 2+y, \\
1.5-z\end{array}$ \\
\hline & I3 $\cdots$ I9(iii) & $\begin{array}{c}3.9537 \\
(6)\end{array}$ & $\begin{array}{l}\text { C7-I3-I9(iii) } \\
=126.9(1), \\
\text { C17(ii)- } \\
\text { I9(iii)-I3 = } \\
128.9(1)\end{array}$ & 3.96 & 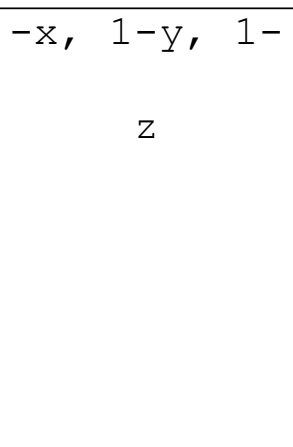 \\
\hline & I5 $\cdots$ O $6^{\text {(iv) }}$ & $2.945 \quad(3)$ & 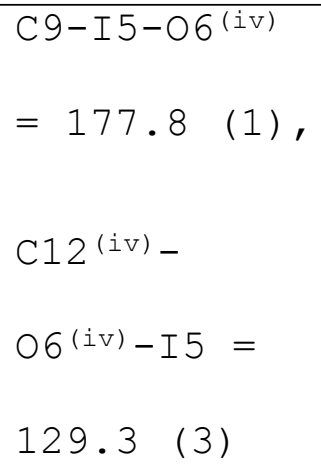 & 3.5 & $\begin{array}{c}x, 1.5-y,- \\
1 / 2+z\end{array}$ \\
\hline & I6 $\cdots .02^{(i)}$ & $3.092 \quad(3)$ & $\begin{array}{l}\text { C14-I6-O2 (i) } \\
=170.6(1), \\
C 3^{(i)}-02^{(i)}-I 6 \\
=120.8\end{array}$ & 3.5 & $\begin{array}{c}x, 1 / 2-y, \\
1 / 2+z\end{array}$ \\
\hline
\end{tabular}

Upon removal of a -COOH group from PIBA, all iodines should become equal and reveal similar properties in terms of their XB donor ACS Paragon Plus Environment 
ability. Our calculations of hexaiodobenzene (polymorphs 6a - 6c) 34,35 indeed confirmed that $V_{S, \max }(=0.043)$ value is equal for all iodines I1-I3, I1B-I3B. According to the crystal structure analysis of hexaiodobenzene (polymorphs $\mathbf{6 a}-\mathbf{6 c})$, iodines in two polymorphs $\mathbf{6} \mathbf{a}$ and $\mathbf{6} \mathbf{b}$ demonstrate similar XB behavior. Thus, in $\mathbf{6 a}$ two iodines $I 1$ and $I 1 B$ act as XB donors $\left(\mathrm{C}-\mathrm{I} \cdots I=174.65^{\circ}\right.$ and $\mathrm{I} \cdots I$ $=3.766 \AA$ A), two other iodines I3 and I3B act as XB acceptors (C$I \cdots I 2=124.28^{\circ}$ and $I \cdots I=3.777^{\circ}$ ) and the last two iodines I2 and $\mathrm{I} 2 \mathrm{~B}$ act both as XB donors and XB acceptors at the same time $\left(C-I \cdots I=114.74^{\circ}\right.$ and $176.94^{\circ}, I \cdots I=3.766^{\circ}$ and $\left.3.777^{\circ}\right)$. In $6 b$ iodines $I 3$ and $I 3 B$ act $a s$ XB donors $\left(\mathrm{C}-\mathrm{I} \cdots I=173.47^{\circ}\right.$ and $\mathrm{I} \cdots I=$

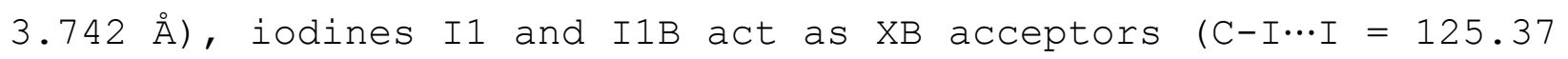
- and $I \cdots I=3.75 \AA$ ) and iodines $I 2$ and $I 2 B$ act both as XB donors and $\mathrm{XB}$ acceptors at the same time $\left(\mathrm{C}-\mathrm{I} \cdots I=176.41^{\circ}\right.$ and $116.29^{\circ}$, $I \cdots I=3.747 \AA$ and $3.742 \AA)$. Finally, in the third polymorph $6 \mathbf{c}$ all iodine atoms act as XB donors and XB acceptors (see Table 5). Interestingly, in 6c polymorph I1, I2 and I3 form an XB triangle

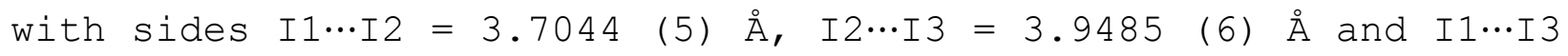
$=3.7125$ (6) $\AA$ (Figure 13). In all three polymorphs XB angles are close to $90^{\circ}$ and $180^{\circ}$, but not exactly because of the steric hindrances. Still all the XB interactions can be considered as type II contacts with I..I distances being less than the sum of vdW radii $(3.96 \AA)$. 
Table 5. Halogen bonds in $6 \mathbf{a}-\mathbf{6 c}$.

\begin{tabular}{|c|c|c|c|c|c|}
\hline & Atoms & $\begin{array}{c}\text { Distance, } \\
\AA\end{array}$ & Angles, & $\begin{array}{c}\text { Sum of } \\
\text { vdW } \\
\text { radi } i, \AA\end{array}$ & $\begin{array}{l}\text { Equivalent } \\
\text { positions } \\
\text { of (i)- } \\
\text { (vii) }\end{array}$ \\
\hline \multirow[t]{2}{*}{$6 a$} & I1 $\cdots$ I2 ${ }^{(i)}$ & 3.766 & $\begin{array}{l}C 1-I 1-I 2^{(i)} \\
=174.65, \\
C 2^{(i)}-I 2^{(i)}- \\
I 1= \\
114.74\end{array}$ & 3.96 & $\begin{array}{l}1 / 2-\mathrm{x},- \\
1 / 2+\mathrm{y}, \\
1 / 2-\mathrm{z}\end{array}$ \\
\hline & I3 $\cdots I_{2} B^{(i i)}$ & 3.777 & $\begin{array}{l}\mathrm{C} 3-\mathrm{I} 3- \\
\mathrm{I} 2 \mathrm{~B}^{(\mathrm{ii})}= \\
124.28, \\
\mathrm{C} 2 \mathrm{~B}^{(\mathrm{ii})}- \\
\mathrm{I} 2 \mathrm{~B}^{(\mathrm{ii})}-\mathrm{I3}= \\
176.94\end{array}$ & 3.96 & $\begin{array}{l}-1 / 2+x, \\
1 / 2-y, \\
1 / 2+z\end{array}$ \\
\hline $6 b$ & I2 $\cdots$ I1 (iii) & 3.75 & $\begin{array}{l}\mathrm{C} 2-\mathrm{I} 2- \\
\mathrm{I} 1^{\text {(iii) }}= \\
176.41^{\prime} \\
\mathrm{C} 1^{\text {(iii)_- }}\end{array}$ & 3.96 & $\begin{array}{l}1-x,- \\
1 / 2+y, \\
1 / 2-z\end{array}$ \\
\hline
\end{tabular}




\begin{tabular}{|c|c|c|c|c|c|}
\hline & & & $\begin{array}{l}I 1^{(\text {iii) }}-I 2= \\
125.37\end{array}$ & & \\
\hline & 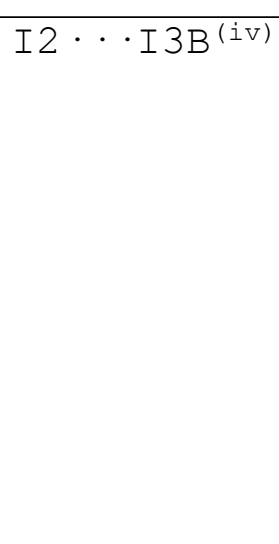 & 3.742 & $\begin{array}{l}\mathrm{C} 2-\mathrm{I} 2- \\
\mathrm{I} 3 \mathrm{~B}^{\text {(iv) }}= \\
116.29, \\
\mathrm{C} 3 \mathrm{~B}^{\text {(iv) }-} \\
\mathrm{I3} \mathrm{B}^{\text {(iv) }}-\mathrm{I} 2= \\
173.47\end{array}$ & 3.96 & $\begin{array}{c}x, 1 / 2-y, \\
1 / 2+z\end{array}$ \\
\hline \multirow[t]{3}{*}{$6 c$} & $\mathrm{I} 2 \cdots \mathrm{I}^{(\mathrm{v})}$ & $\begin{array}{c}3.7044 \\
(5)\end{array}$ & $\begin{array}{l}\mathrm{C} 1-\mathrm{I} 2-\mathrm{I} 1^{(\mathrm{v})} \\
=174.2 \\
(1), \mathrm{C} 3^{(\mathrm{v})}- \\
\mathrm{I} 1^{(\mathrm{v})}-\mathrm{I} 2= \\
114.9 \quad(1)\end{array}$ & 3.96 & $\begin{array}{l}1.5-x, \\
1 / 2+y, \\
1.5-z\end{array}$ \\
\hline & I1 $\cdots$ I3 $^{(v i)}$ & $\begin{array}{c}3.7125 \\
(6)\end{array}$ & $\begin{array}{l}\mathrm{C} 3-\mathrm{I} 1-\mathrm{I} 3^{(\mathrm{vi})} \\
=178.3 \\
(1)^{\mathrm{C}} \mathrm{C} 2^{(\mathrm{vi})}- \\
\mathrm{I} 3^{(\mathrm{vi})}-\mathrm{I} 1^{=} \\
124.6 \text { (1) }\end{array}$ & 3.96 & $\begin{array}{l}2.5-x, \\
1 / 2+y \\
1.5-z\end{array}$ \\
\hline & I2 $\cdots$ I3 $^{\text {(vii) }}$ & $\begin{array}{c}3.9485 \\
(6)\end{array}$ & $\begin{array}{l}\mathrm{C} 1-\mathrm{I} 2- \\
\mathrm{I} 3^{\text {(vii) }}= \\
123.5(1), \\
\mathrm{C} 2^{\text {(vii) - }}\end{array}$ & 3.96 & $\begin{array}{c}-1+x, 1+y, \\
z\end{array}$ \\
\hline
\end{tabular}

ACS Paragon Plus Environment 


\begin{tabular}{|l|l|l|l|l|l|}
\hline & & & I3(vi) - I2 $=$ & \\
$173.6 \quad(1)$ & & & \\
& & & & \\
\hline
\end{tabular}

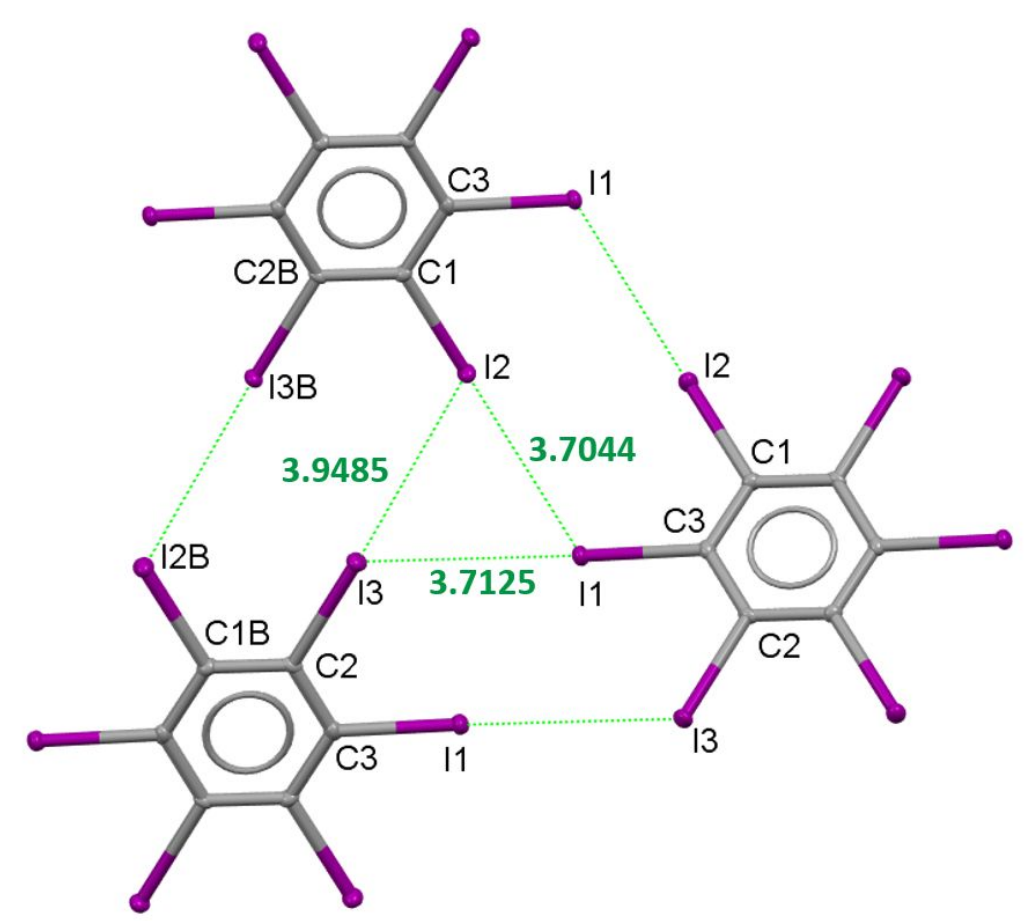

Figure 13. Halogen bond triangle in the structure of $\mathbf{6 c}$. Selected bond lengths ( $\AA$ ) and angles $\left({ }^{\circ}\right)$ : I1-I2(i) 3.7044 (5), I1-I3(ii) 3.7125 (6), I2 (i) $-I 3^{(i i)} 3.9485$ (6), $C 1^{(i)}-I 2^{(i)}-I 1174.2$ (1), C3-I1-I2(i) 114.9 (1), C3-I1-I3(ii) 178.3 (1), C2 (ii)-I3(ii)-I1 124.6 (1), C1 (i)I2(i) $-I 3^{(i i)} 123.5$ (1), $\quad C 2^{(i i)}-I 3^{(i i)}-I 2^{(i)} 114.9$ (1). Equivalent positions: (i) $1.5-x,-1 / 2+y, 1.5-z$; (ii) $2.5-x, 1 / 2+y, 1.5-z$. When comparing hexaiodobenzene (HIB) and PIBA we can conclude, that the difference in the XB behavior of iodines arises not from the electron-withdrawing properties of a carboxyl group, but is 
due to the steric factors as well as strong hydrogen bonding between a -COOH group and ethanol. The revealed difference in the calculated electrostatic potentials of iodine atoms $\left(V_{\mathrm{S}, \max (\mathrm{PIBA})}=\right.$ $\left.0.047 / 0.050, V_{S, \max (\mathrm{HIB})}=0.043\right)$ is due to the extensive hydrogen bonding between the carboxyl group and ethanol in the structure of 5 .

It should also be noted that both PIBA and HIB reveal intramolecular I...I contacts similar to TIBA. The corresponding I... I distances are found in Table 6 .

Table 6. The intramolecular I...I distances in compounds 5 and 6 .

\begin{tabular}{|c|c|c|}
\hline Compound & Atoms & Distance, $\AA$ \\
\hline \multirow{7}{*}{5} & 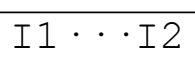 & 3.548 \\
\hline & I2 $\cdots$ I3 & 3.546 \\
\hline & I3 $\cdots$ I4 & 3.524 \\
\hline & I4 $\cdots$ I5 & 3.551 \\
\hline & I6 $\cdots$ I7 & 3.564 \\
\hline & 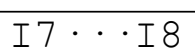 & 3.512 \\
\hline & 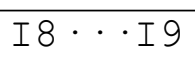 & 3.508 \\
\hline
\end{tabular}

ACS Paragon Plus Environment 


\begin{tabular}{|c|c|c|}
\hline & I9 $\cdots$ I10 & 3.536 \\
\hline \multirow{3}{*}{$6 a$} & $\begin{array}{c}\text { I3 } \cdots \text { I2B }= \\
\text { I3B } \cdots \text { I2 }\end{array}$ & 3.501 \\
\hline & 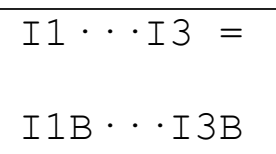 & 3.500 \\
\hline & $\begin{array}{c}I 3 \cdots I 2 B= \\
I 2 \cdots I 3 B\end{array}$ & 3.521 \\
\hline \multirow{3}{*}{$6 b$} & $\begin{array}{l}I 1 \cdots I 2= \\
I 1 B \cdots I 2 B\end{array}$ & 3.500 \\
\hline & $\begin{array}{l}I 1 \cdots I 3= \\
I 1 B \cdots I 3 B\end{array}$ & 3.49 \\
\hline & $\begin{array}{c}I 3 \cdots I 2 B= \\
\text { I3B } \cdots I 2\end{array}$ & 3.49 \\
\hline \multirow[t]{3}{*}{$6 c$} & $\begin{array}{l}I 1 \cdots I 2= \\
I 1 B \cdots I 2 B\end{array}$ & $3.4974 \quad(6)$ \\
\hline & $\begin{array}{l}I 1 \cdots I 3= \\
I 1 B \cdots I 3 B\end{array}$ & $3.5182 \quad(5)$ \\
\hline & $\begin{array}{c}I 3 \cdots I 2 B= \\
I 3 B \cdots I 2\end{array}$ & $3.5096(6)$ \\
\hline
\end{tabular}

ACS Paragon Plus Environment 
In order to explore the influence of the strength of a stronger electron-withdrawing group on the XB donor-acceptor behavior of iodine atoms, the 4-iodobenzonitrile (7) and 3-iodobenzonitrile $^{37}$ (8) were taken into consideration (Figure 14, Table 7). Accordingly, in the structure of $\mathbf{7}$ the iodine atom Il in paraposition should act as an XB donor due to the strong negative mesomeric effect of a nitrile group -CN. On the contrary, in a compound $\mathbf{8}$ iodine $\mathbf{I}$ in meta-position relative to a -CN group should act as an XB acceptor. The structural analysis on these two iodobenzonitriles show the formation of a strong I1 $\cdots \mathrm{N} 1$ bonding in the structure of $\mathbf{7}$, in which para-iodine I1 acts as an XB donor. The I1-N1 distance is equal to $3.123 \AA$ (the sum of vdW radii is $3.53 \AA$ ) and the C1-I1-N1 angle is equal to $180.0^{\circ}$. In the structure of 8 the iodine atom Il acts as an XB donor and an XB acceptor upon interaction with iodines from two adjacent 3-iodobenzonitrile molecules (Figure 14, Table 7). The I1-I1 distance is 3.806 (1) $\AA$ Vs. the sum of van der Waals radii being $3.96 \AA$. In contrast to 7, nitrogen atoms in $\mathbf{8}$ are involved in a hydrogen bonding and do not form XBs with iodine atoms.

Our calculations of the maximum of the electrostatic potential surface revealed, that the $V_{S, \max }$ values for Il atoms of $\mathbf{7}$ and $\mathbf{8}$ are almost equal, being 0.042 for 7 and 0.041 for 8 . However, the demonstrated difference in the XB donor-acceptor behavior of these 
iodine atoms support our hypothesis, that a substituent other than halogen does have an impact on the XB donor-acceptor behavior of the halogens in a benzene ring. Specifically, para-iodine in 7 acts a strong XB donor, while in the structure of $\mathbf{8}$, the XB donor ability of meta-iodine is less pronounced, and it acts both as an XB donor and as an XB acceptor.

Furthermore, there is a clear difference between the behavior of para-iodines in compounds $\mathbf{4}$ and $\mathbf{7}$. While para-iodine in the structure of $\mathbf{7}$ demonstrates strong XB donor properties (calculated $\left.V_{\mathrm{S}, \max }=0.042\right)$, para-iodine in the structure of $\mathbf{4}$ reveals both $\mathrm{XB}$ donor and XB acceptor properties (calculated $V_{S}$, max $=0.035$ ). This fact, supported by our calculations, shows that not only the position of the halogen atom in a benzene ring, but also the ability of the electron-withdrawing substituent to withdraw electron density from a benzene ring affects the XB donor-acceptor behavior of halogens. 


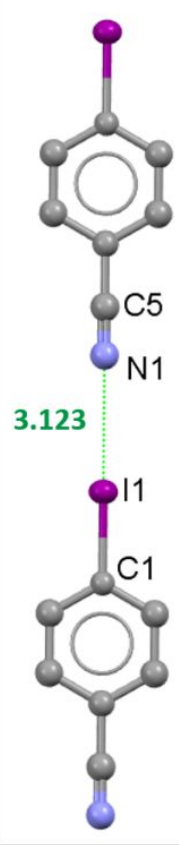

a

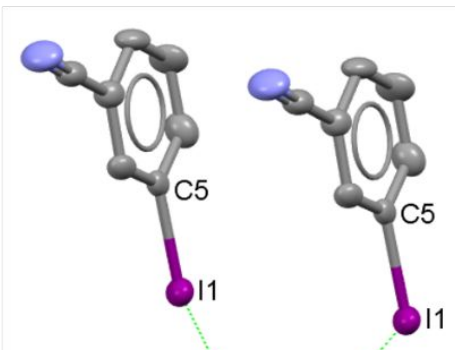

3.806 3.806

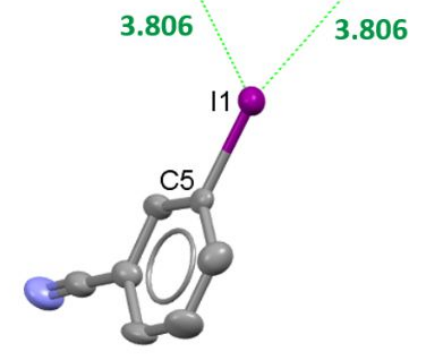

b

Figure 14. Halogen bonding in the structures of 7 (a) and 8 (b) . Hydrogens are omitted for clarity. Selected bond lengths (Å) and angles $\left({ }^{\circ}\right):$ (a) $\mathrm{I} 1-\mathrm{N} 1^{(\mathrm{i})} 3.123, \mathrm{C} 1-\mathrm{I} 1-\mathrm{N1}{ }^{(\mathrm{i})} 180.0, \quad \mathrm{C} 5^{(\mathrm{i})}-\mathrm{N} 1^{(\mathrm{i})}-\mathrm{I} 1$ $180.0 ;$ (b) I1-I1 (ii) 3.806 (1), I1-I1(iii) 3.806 (1), C5-I1-I1 (ii) 165.4 (2), C5 (ii) $-I 1^{(i i)}-I 1128.3$ (2), C5-I1-I1(iii) 128.3 (2), C5 (iii)I1(ii)-I1 165.4 (2). Equivalent positions: (i) $x,-1+y, z$; (ii) $1 / 2-x,-1 / 2+y, 1 / 2-z ;$ (iii) 1/2-x, 1/2+y, 1/2-z .

Table 7. Halogen bonds in 7 and 8 .

\begin{tabular}{|c|c|c|c|c|c|}
\hline Atoms & $\begin{array}{c}\text { Distance, } \\
\text { Angles, }\end{array}$ & Sum of & Equivalent \\
& & & vdW & positions \\
& & & radii, $\AA$ & \\
\hline
\end{tabular}

ACS Paragon Plus Environment 


\begin{tabular}{|c|c|c|c|c|c|}
\hline & & & & & $\begin{array}{l}\text { of }(i)- \\
(i i i)\end{array}$ \\
\hline 7 & $\mathrm{I1} \cdot \mathrm{N}^{(\mathrm{i})}$ & 3.123 & $\begin{array}{l}\mathrm{C} 1-\mathrm{I} 1-\mathrm{N} 1^{(\mathrm{i})} \\
=180.0, \\
\mathrm{C} 5^{(\mathrm{i})}-\mathrm{N} 1^{(\mathrm{i})}- \\
\mathrm{I} 1=180.0\end{array}$ & 3.53 & $x,-1+y, \quad z$ \\
\hline 8 & 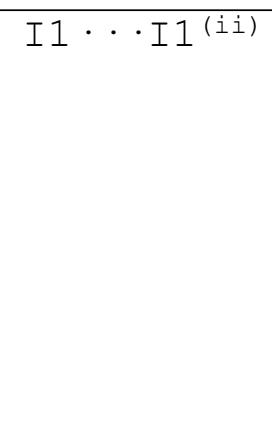 & 3.806 (1) & $\begin{array}{l}\text { C5-I1-I1 (ii) } \\
=165.4 \\
(2), C 5^{(i i)}- \\
I 1^{(i i)}-I 1= \\
128.3 \quad \text { (2) }\end{array}$ & 3.96 & $\begin{array}{c}1 / 2-x,- \\
1 / 2+y \\
1 / 2-z\end{array}$ \\
\hline & I1 $\cdots$ II $^{\text {(iii) }}$ & $3.806 \quad(1)$ & $\begin{array}{l}\text { C5-I1- } \\
\text { I1 (iii) }= \\
128.3 \text { (2), } \\
C 5{ }^{\text {(iii) }-} \\
I 1^{(\text {iii) }}-I 1= \\
165.4 \text { (2) }\end{array}$ & 3.96 & $\begin{array}{l}1 / 2-x, \\
1 / 2+y \\
1 / 2-z\end{array}$ \\
\hline
\end{tabular}

According to the above consideration, the replacement of the $-\mathrm{M}$ substituent to $+M$ substituent should change the distribution of an electron density in a benzene ring as well as make an impact on the XB donor-acceptor behavior of iodide substituents. To verify 
this hypothesis, we have studied 2,4-diiodoaniline (9), 4iodoaniline (10), 2-iodoaniline (11), 2-iodophenol (12), 4iodophenol (13), 3-iodophenol (14), 2,4,6-triiodophenol (15), 4iodoanisole (16) and 3,4,5-triiodoanisole (17). Thus, when carboxyl group is changed to an electron-donating group with a positive mesomeric effect (like $-\mathrm{NH}_{2}$, $-\mathrm{OH}$ and $-\mathrm{OCH}_{3}$ ), the electron density redistributes in the opposite direction (Figure 3), making ortho- and para- positions favorable XB acceptors and metapositions favorable XB donors.

Among the hitherto known structures, in 2,4-diiodoaniline (9) ${ }^{38}$ para-iodine I2 interacts only with the $\pi$-system of a benzene ring and in 4-iodoaniline (10) ${ }^{39}$ there are no halogen or hydrogen bonds. But in 2-iodoaniline (11) ${ }^{40}$ iodines $I 1$ form I ‥ contacts acting both as XB donor and XB acceptor $\left(\mathrm{C} 2-\mathrm{I} 1 \cdots \mathrm{I} 1^{(i)}=172.7\right.$ (2) ${ }^{\circ}$ and $I 1 \cdots I 1^{(i)}=3.799$ (2) $\AA, C 2^{(i)}-I 1^{(i)} \cdots I 1=107.2$ (2) ${ }^{\circ}$ and $I 1^{(i)} \cdots I 1=$ 3.799 (2) $\AA$; equivalent position of (i) is $-x+y,-x, 1 / 3+z)$. When moving from iodoanilines to iodophenols, in 2-iodophenol (12) ${ }^{41}$ iodine atoms Il form only type I contacts and in 4-iodophenol (13) ${ }^{37}$ iodines I1 interact with a benzene ring. Iodine atoms I1 and I3 show the XB donor and the XB acceptor behavior in 3-iodophenol $(\mathbf{1 4})^{37}\left(\mathrm{C} 1-\mathrm{I} 1 \cdots \mathrm{O} 1=157.92^{\circ}\right.$ and $\left.\mathrm{I} 1 \cdots \mathrm{O} 1=3.332 \AA\right)$ and $2,4,6-$

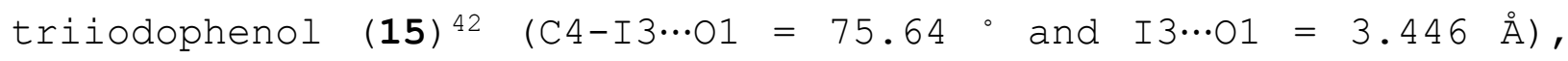
correspondingly. 
In order to demonstrate the effect of $+\mathrm{M}$ substituent, a methoxy $\mathrm{OCH}_{3}$ substituent was selected. Thus, in 4-iodoanisole (16) 43 (Figure 15, Table 8) a positive mesomeric effect of the methoxy group should favor iodine in para-position to act as a halogen bond acceptor. However, according to the structural analysis, an iodine atom I1 participates in a weak interaction with an oxygen atom 01 from the ether group of an adjacent molecule and acts as

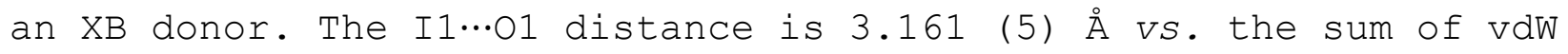
radii of $3.50 \AA$, the $\mathrm{C}-\mathrm{I} \cdots \mathrm{O}$ angle is 172.1 (2) . The calculated $V_{\mathrm{S}, \max }$ value for I1 is 0.025. If we compare three structures, 4iodoaniline (10), 4-iodophenol (13) and 4-iodoanisole (16), we can see, that although for all these structures the $V_{S \text {, max }}$ value for para-iodine is very similar $(0.021$ for 10, 0.026 for 13 and 0.025 for 16), the XB donor-acceptor behavior differs significantly. Thus, in a case of stronger electron-donating substituents $-\mathrm{NH}_{2}$ (10) and $-\mathrm{OH}$ (13) the iodine atoms do not participate in a halogen bonding. It can be explained by the fact, that in both structures 10 and 13 electrons on the nitrogen and oxygen atoms are hindered by the broad region of a positive electrostatic potential (Figure 17), which is reflected in the $V_{S \text {, max }}$ values being $0.050-0.068$ for the amino group and 0.061-0.075 for the hydroxy group (Table S4). This makes impossible the I..N and I..O interactions to happen. 
In a case of the methoxy $-\mathrm{OCH}_{3}$ substituent, which reveals a much weaker positive mesomeric effect, the para-iodine atom Il acts as an $\mathrm{XB}$ donor upon interaction with oxygen from a neighboring molecule (16). According to our computational analysis, a region with a positive electrostatic potential from $\mathrm{CH}_{3}$ in shifted to the side, thus, opening a negative region on oxygen and giving space for iodine to approach (Figure 17). This is also confirmed by a very small $V_{S, \max }$ value on oxygen o1 (0.009).

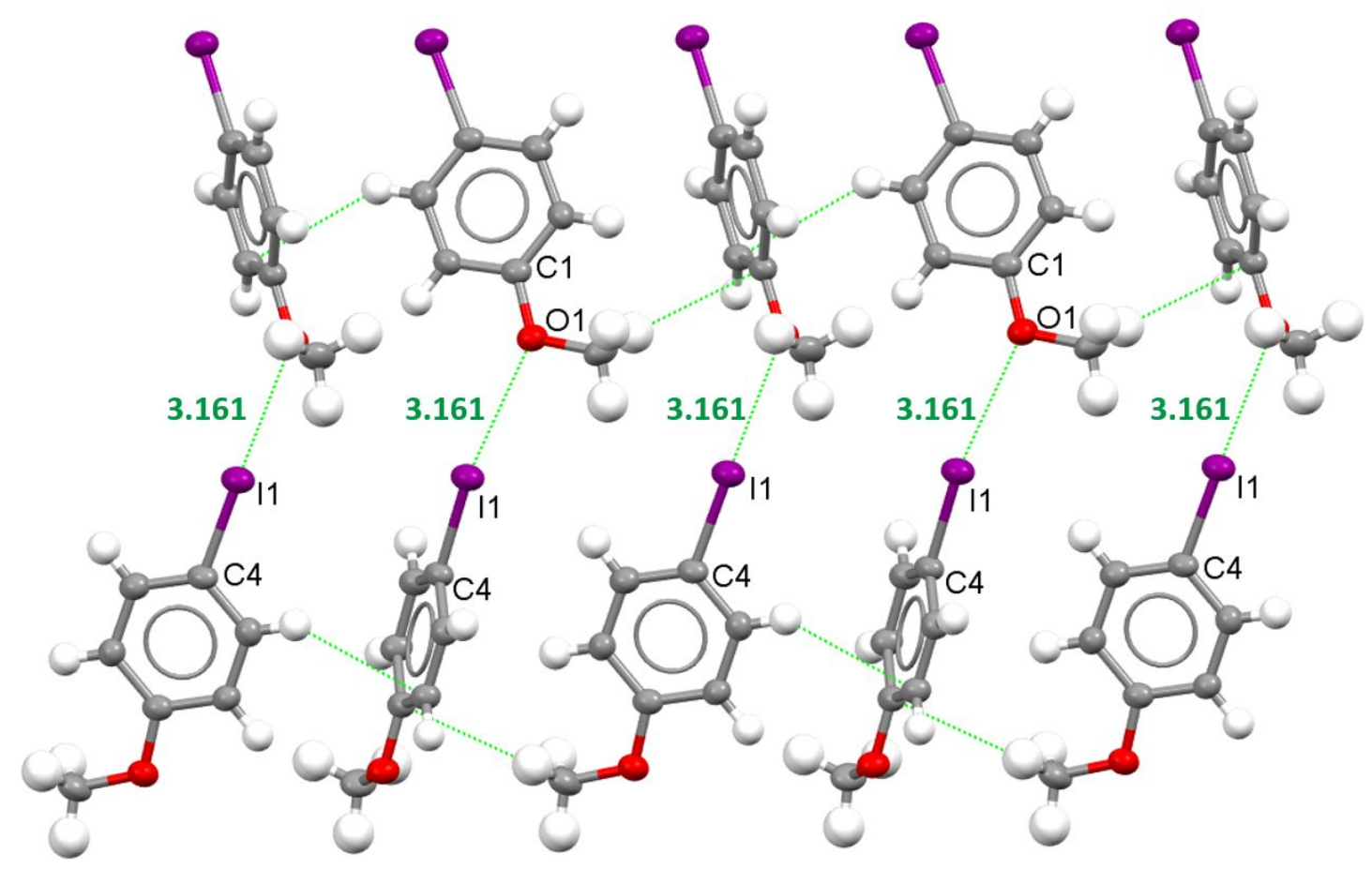

Figure 15. Weak interactions in the structure of 16. Selected bond

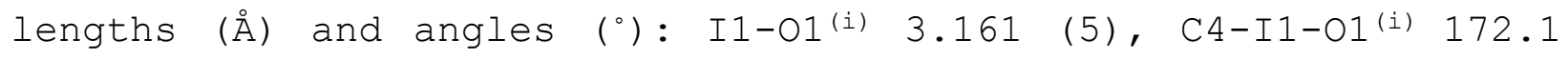
(2), $\mathrm{C} 1^{(i)}-\mathrm{O} 1^{(i)}-\mathrm{I} 1$ 129.4 (4). Equivalent positions: (i) 1.5-x, y, $1 / 2+z$ 
Table 8. Halogen bonds in 11 and 14-17.

\begin{tabular}{|c|c|c|c|c|c|}
\hline & Atoms & $\begin{array}{c}\text { Distance, } \\
\AA\end{array}$ & Angles, ${ }^{\circ}$ & $\begin{array}{l}\text { Sum of } \\
\text { vdw } \\
\text { radii, } \\
\AA\end{array}$ & $\begin{array}{l}\text { Equivalent } \\
\text { positions } \\
\text { of (i-vii) }\end{array}$ \\
\hline 11 & $I 1 \cdots I 1^{(i)}$ & $3.799 \quad(2)$ & $\begin{array}{l}C 2-I 1-I 1^{(i)} \\
=107.2 \\
(2), C 2^{(i)}- \\
I 1^{(i)}-I 1= \\
172.7 \quad(2)\end{array}$ & 3.96 & $\begin{array}{c}-x+y,-x, \\
1 / 3+z\end{array}$ \\
\hline 14 & I1 $\cdots O 1^{(i i)}$ & $3.332 \quad(3)$ & $\begin{array}{l}C 1-I 1-O 1^{(i i)} \\
=157.9 \\
(1)^{\prime} \\
C 4^{(i i)}- \\
O 1^{(i i)}-I 1= \\
102.8 \quad(3)\end{array}$ & 3.5 & $\begin{array}{c}1 / 2-x, 1-y, \\
-1 / 2+z\end{array}$ \\
\hline 15 & I3 $\cdots$ O1 ${ }^{\text {(iii) }}$ & $3.446 \quad(8)$ & $\begin{array}{l}\text { C4-I3- } \\
\text { O1(iii) }= \\
75.6 \text { (3), }\end{array}$ & 3.5 & $\begin{array}{c}1 / 2+x, \quad 1 / 2- \\
y, \quad-z\end{array}$ \\
\hline
\end{tabular}




\begin{tabular}{|c|c|c|c|c|c|}
\hline & & & $\begin{array}{l}\mathrm{C} 3^{(\mathrm{iii})}- \\
\mathrm{O} 1^{(\mathrm{iii})}-\mathrm{I} 3= \\
154.1\end{array}$ & & \\
\hline 16 & I1 $\cdots O 1^{(i v)}$ & $3.161 \quad(5)$ & $\begin{array}{l}\mathrm{C} 4-\mathrm{I} 1-\mathrm{O} 1^{\text {(iv) }} \\
=172.1 \\
(2), \\
\mathrm{C} 1^{(\mathrm{iv})}- \\
\mathrm{O} 1^{(\mathrm{iv})}-\mathrm{I} 1= \\
129.4 \quad(4)\end{array}$ & 3.5 & $\begin{array}{c}1.5-x, y, \\
1 / 2+z\end{array}$ \\
\hline 17 & I1 $\cdots$ I3 (v) & $\begin{array}{c}3.9294 \\
(5)\end{array}$ & $\begin{array}{l}C 3-I 1-I 3^{(v)} \\
=160.8 \\
(1), \\
C 5^{(v)}-I 3^{(v)}- \\
I 1=82.7 \\
(1)\end{array}$ & 3.96 & $\begin{array}{c}-x, 1 / 2+y, \\
1 / 2-z\end{array}$ \\
\hline & $\mathrm{I} 2 \cdots \mathrm{O} 1^{(\mathrm{vi})}$ & $3.270 \quad(3)$ & $\begin{array}{l}\mathrm{C} 4-\mathrm{I} 2-\mathrm{O} 1^{\text {(vi) }} \\
=177.2 \\
(1)^{\prime} \\
\mathrm{C} 1^{\text {(vi) }^{-}} \\
\mathrm{O} 1^{\text {(vi) }-\mathrm{I} 2=} \\
126.6 \text { (3) }\end{array}$ & 3.50 & $\begin{array}{l}-1+x, 1 / 2- \\
y, \quad-1 / 2+z\end{array}$ \\
\hline
\end{tabular}




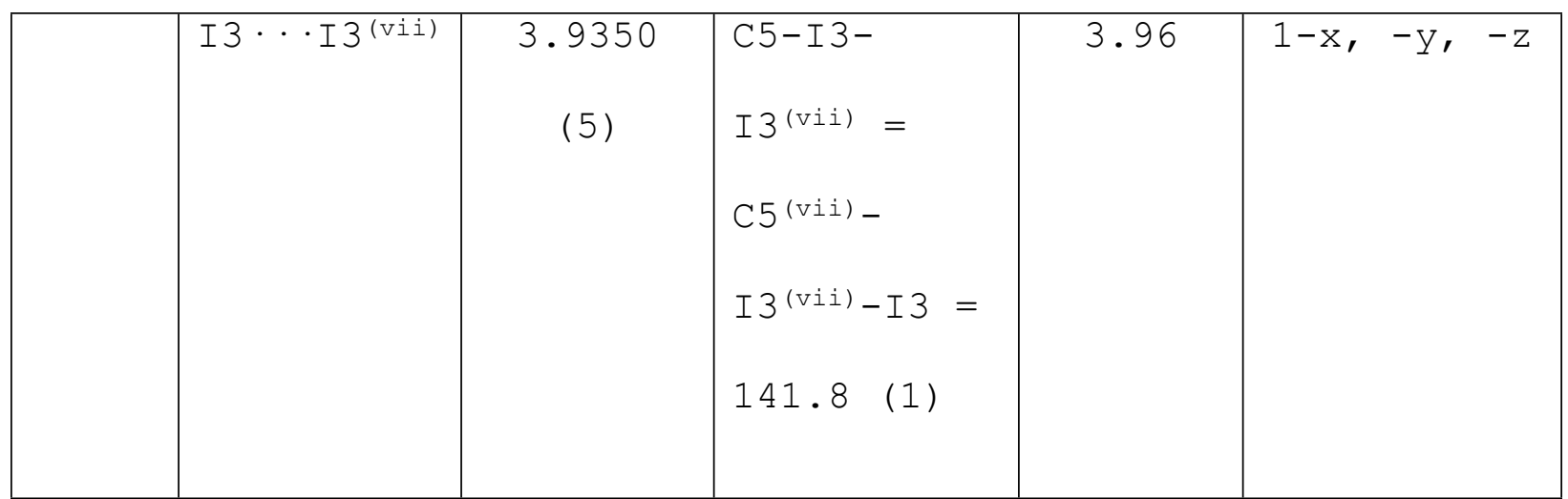

In the structure of 3,4,5-triiodoanisole (17) ${ }^{44}$ an iodine atom in para-position should favor XB acceptor behavior and two iodines in meta-positions should favor XB donor behavior because of the $+\mathrm{M}$ effect of a methoxy group $-\mathrm{OCH}_{3}$. According to the crystal structure analysis, all three iodine atoms reveal different XB activity (Figure 16, Table 8). Thus, meta-iodine I1 acts as an XB donor with the I3 atom from an adjacent molecule. The corresponding I1‥I3 distance is 3.9294 (5) $\AA$ Vs. the sum of vdW radii of $3.96 \AA$, the C3-I1…3 angle is 160.8 (1) * Another meta-iodine I3 acts as an XB acceptor with the I1 atom from an adjacent molecule (I3-I1 = 3.9294 (5) $\AA$, C5-I3-I1 = 82.7 (1) ${ }^{\circ}$ ) and also forms type I contacts with an another I3 atom. Finally, para-iodine I2 acts as an XB donor and interacts with the oxygen atom 01 from adjacent molecule with $I 2-01=3.270$ (3) $\AA, C 4-I 2-01=177.2 \quad$ (1) ${ }^{\circ}$.

The calculated $V_{S, \max }$ values for the iodine atoms of $\mathbf{1 7}$ are 0.034 , 0.033 and 0.036 for I1, I2 and I3, respectively. These values together with the XB donor-acceptor behavior of iodines in 17 let 
us assume that the weak positive mesomeric effect of an ether group $-\mathrm{OCH}_{3}$ does not affect the iodine atoms to a large extent. Furthermore, upon a comparison of compounds 16 and 17, it can be clearly seen that the $V_{S, \max }$ numbers on para-iodines differ significantly $(0.025$ for 16 and 0.033 for 17), thus, resulting in an assumption, that meta-iodines in 17 have a higher impact on the chemical properties of para-iodine than the methoxy group.

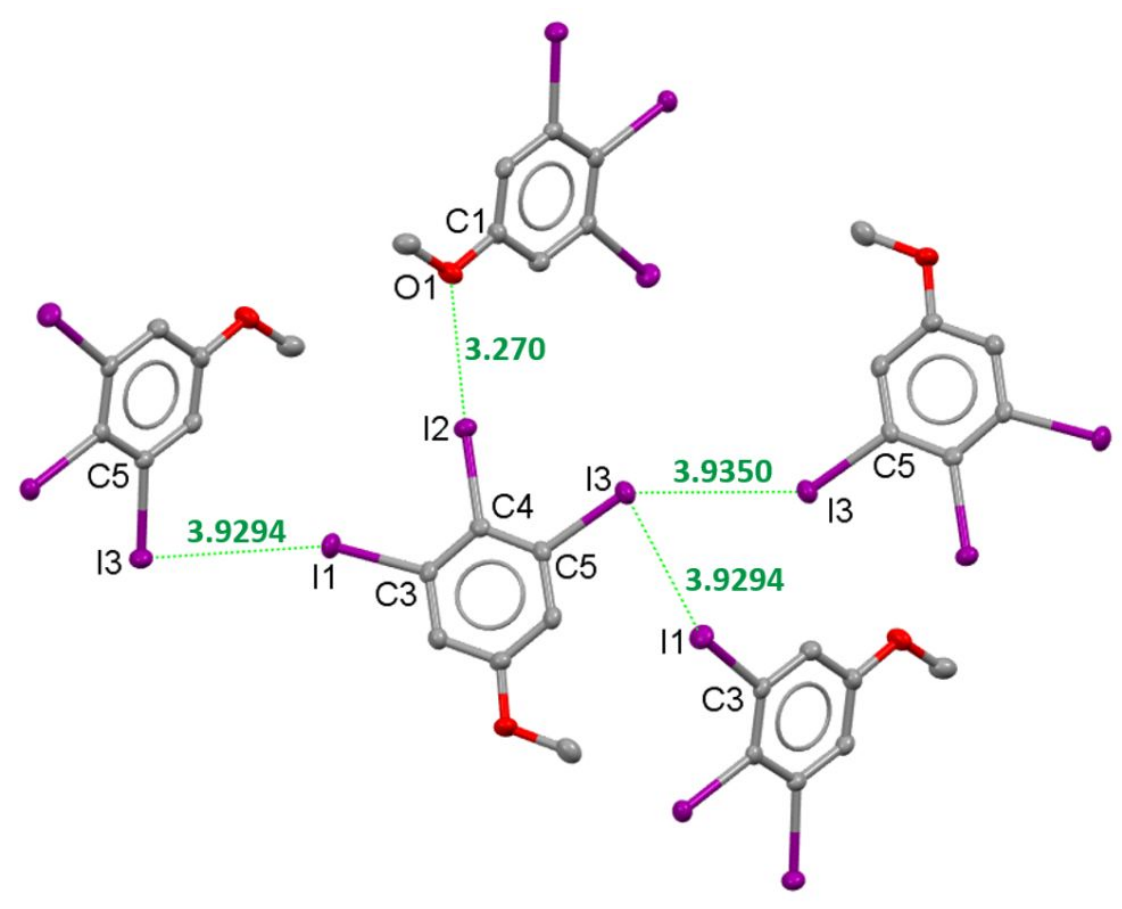

Figure 16. Halogen bonding in the structure of 17. Hydrogens are omitted for clarity. Selected bond lengths ( $)$ and angles $\left({ }^{\circ}\right)$ : I1I2(i) 3.7044 (5), I1-I3(ii) 3.7125 (6), I2(i)-I3(ii) 3.9485 (6), C1 (i)I2 (i) $-\mathrm{I} 174.2$ (1), C3-I1-I2(i) 114.9 (1), C3-I1-I3(ii) 178.3 (1),

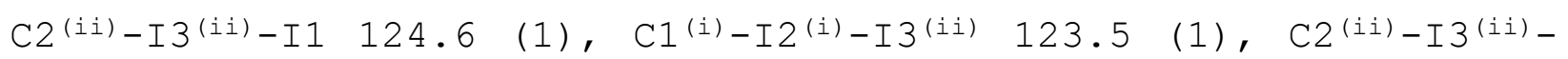


I2(i) 114.9 (1). Equivalent positions: (i) $1.5-x,-1 / 2+y, 1.5-z$; (ii) $2.5-x, 1 / 2+y, 1.5-z$.

2.3. Computational analysis

Analysis of the map of electrostatic potential (further MEP) helps to predict and estimate non-covalent interactions. ${ }^{74,75}$ It was shown that the magnitude of the sigma-hole (further $V_{\mathrm{S}, \max }$ ) correlates with the strength of a non-covalent interaction. ${ }^{74,76}$ Moreover, groups of substituents with electron-donating (EDG) or electronwithdrawing (EWG) effects can influence $V_{S}$, max and, correspondingly, the interaction strength. EWG can increase $V_{S}$, max by depleting the electron density, while in case of EDG the $V_{\mathrm{S}}$ max may decrease due to the additional electron density in the system.7,76-78

The influence of the substituent on the $V_{S}$, max value of the halide in structures $\mathbf{1 - 1 7}$ can be clearly seen (Figure 17, Table 9, Table S4). Our computational results indeed show, that in the case of the electron-withdrawing groups the $V_{S, \max }$ value of the iodine atom is always bigger, than in the case of the electron-donating groups.

An increase in the $V_{S}$, max values on the iodine atoms can be seen upon introduction of a carboxyl group in the structures of $\mathbf{1 - 2}$ (0.039-0.042) and 5 (0.047-0.050) vs. the structures of $3(0.036)$ and $6(0.043)$. Thus, the difference in the $V_{S, \max }$ values of the iodines in TIBA (1, 2) and 1,2,3-triiodobenzene (3) is due to 
electron-withdrawing effect of a carboxyl group. There is also a small deviation in the $V_{S, \max }$ values between meta- and parapositions in TIBA, with a higher value for para-iodine and smaller values for meta-iodines. In the case of PIBA (5) and HIB (6), although the - $\mathrm{COOH}$ group is not located within the same plane with the benzene ring in 5, the increase of $V_{\mathrm{S}, \max }$ on the iodine atom can be still seen comparing to 6 . The highest $V_{S}$, max values are found for ortho-iodines (5), reflecting higher ability of these iodines to act as XB donors, which correlates with the conducted structural analysis.

In iodobenzonitriles $\mathbf{7 - 8}$ the difference in the $V_{S}$, max values of the iodine between meta- and para-positions is neglectable. However, in iodophenols $\mathbf{1 2 - 1 5}$ the $V_{\mathrm{S}}$ max values are increasing in the row of para- < meta- < ortho-, with the highest values in 2,4,6triiodophenol (15) being 0.035 and 0.048 for ortho- and 0.037 for para-position.

In the case of iodoanilines 9-11 the $V_{\mathrm{S}}$ max values for para-position are lower, than for ortho-positions $(0.021$ and $0.027 \mathrm{vs} .0 .027$ and 0.034) with the highest values found for 2,4-diiodoaniline 9.

The presence of several iodine atoms in one molecule affects the $V_{\mathrm{S}, \max }$ value of iodide substituents due to the $+\mathrm{M}$ effect of the iodine. For example, the $V_{S}$ max value for p-iodine in 4-iodoanisole (16) is smaller, than that in 3,4,5-triiodoanisole (17). The 
corresponding values are 0.025 for 16 and 0.033 for 17 . Another example of the same trend can be observed upon comparison of the 2,4-diiodoaniline (9) and 2-iodoaniline (11) structures: the $V_{S}$, max value for o-iodine is higher in the case of diiodoaniline (0.034 for 9 vs. 0.027 for 11).

In order to trace the influence of the nature of the substituent other than halogen on the XB donor-acceptor properties of the iodide substituents, several groups of compounds were considered. Thus, first group is represented by the compounds with three iodide substituents, i.e. 3,4,5-triiodobenzoic acid (1, 2), 1,2,3triiodobenzene (3) and 3,4,5-triiodoanisole (17). The $V_{S}$, max values increase in a row of $\mathbf{1 7}<\mathbf{3}<\mathbf{1}, \mathbf{2}$. Another group is represented by compounds 4-iodobenzoic acid (4), 4-iodobenzonitrile (7), 4iodoaniline (10), 4-iodophenol (13) and 4-iodoanisole (16). All these structures have the iodine atom in para-position. The $V_{S}$ max values increase in a row of $10<16<13<4<7$. Finally, third group is represented by compounds, having iodine in meta-position, namely, 3-iodobenzonitrile (8) and 3-iodophenol (14). The $V_{S}$, max value for iodine in the structure of $\mathbf{8}$ is much higher, than that in the structure of 14. All these correlations confirm our hypothesis, that electron-withdrawing groups withdraw electron density from benzene ring and, therefore, increase the size of a o-hole. On the contrary, electron-donating groups donate electron 
density to the benzene ring, thus, decreasing the size of a $\sigma-$ hole. Therefore, iodide substituents reveal better XB donor ability in the case of electron-withdrawing substituents (1-2, 4, 7-8) and are less likely to act as XB donors in the case of electron-donating substituents (9-17) .

Table 9. Maximum ESP $\left(V_{S, \max }\right)$ of the selected halogenated molecules (calculated at the PBE0-D3/def2-TZVP level).

\begin{tabular}{|c|c|c|}
\hline Molecule & Atom & $V_{\mathrm{S}, \max }, \mathrm{a} \cdot \mathrm{u}$. \\
\hline \multirow{3}{*}{$1,2 *$} & I1 & 0.039 \\
\hline & I2 & 0.042 \\
\hline & I3 & 0.041 \\
\hline \multirow{3}{*}{3} & I1 & 0.036 \\
\hline & I2 & 0.036 \\
\hline & I3 & 0.036 \\
\hline 4 & I1 & 0.035 \\
\hline \multirow{5}{*}{$5 *$} & I1 & 0.049 \\
\hline & I2 & 0.047 \\
\hline & I3 & 0.047 \\
\hline & I4 & 0.047 \\
\hline & I5 & 0.050 \\
\hline \multirow{6}{*}{6} & I1 & 0.043 \\
\hline & I2 & 0.043 \\
\hline & I3 & 0.043 \\
\hline & I1B & 0.043 \\
\hline & I2B & 0.043 \\
\hline & I3B & 0.043 \\
\hline 7 & I1 & 0.042 \\
\hline 8 & I1 & 0.041 \\
\hline \multirow{2}{*}{9} & I1 & 0.034 \\
\hline & I2 & 0.027 \\
\hline 10 & I1 & 0.021 \\
\hline 11 & I1 & 0.027 \\
\hline 12 & I1 & 0.037 \\
\hline 13 & I1 & 0.026 \\
\hline 14 & I1 & 0.029 \\
\hline \multirow{2}{*}{15} & $\mathrm{I1}$ & 0.037 \\
\hline & I2 & 0.048 \\
\hline
\end{tabular}




\begin{tabular}{|l|l|l|}
\hline & I3 & 0.035 \\
\hline \multirow{3}{*}{16} & I1 & 0.025 \\
\hline \multirow{3}{*}{17} & I1 & 0.034 \\
\cline { 2 - 3 } & I2 & 0.033 \\
\cline { 2 - 3 } & I3 & 0.036 \\
\hline
\end{tabular}

*calculations performed for structure omitting the solvent molecule

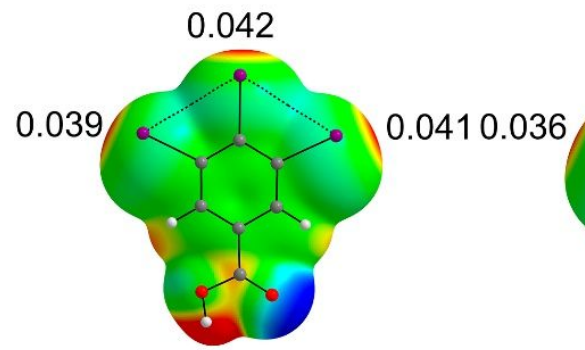

$1,2^{*}$

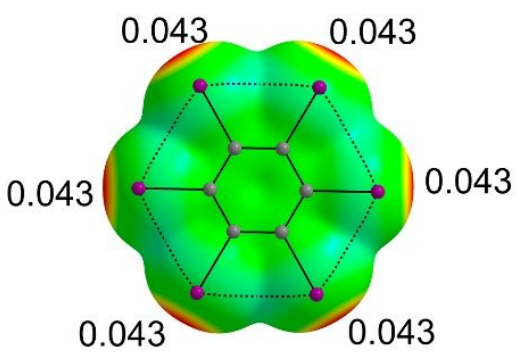

6

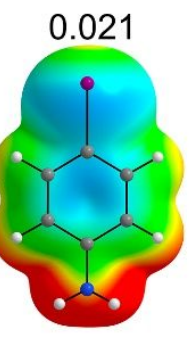

10

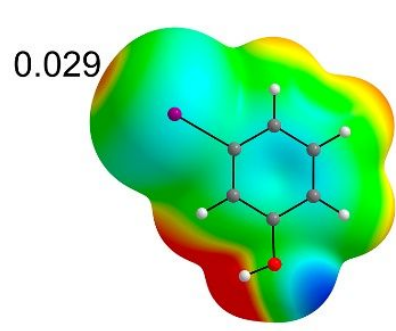

14

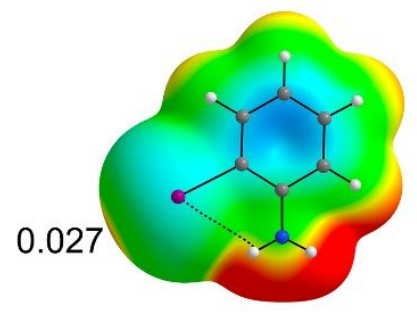

11

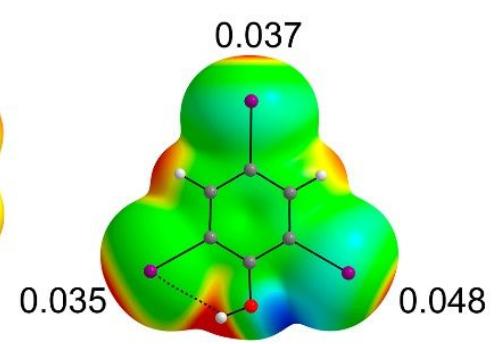

15

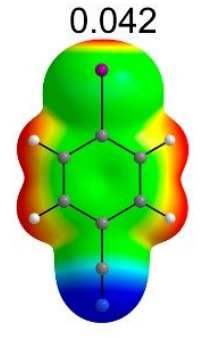

7

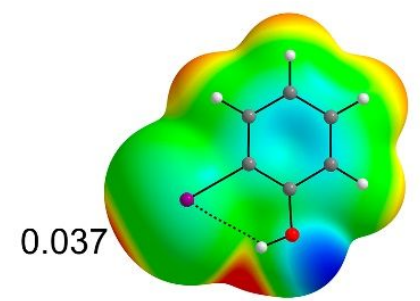

12

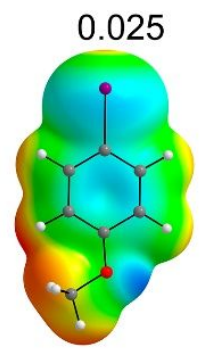

16

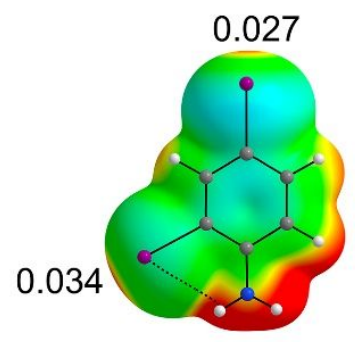

9 0.047 0.049 0.050

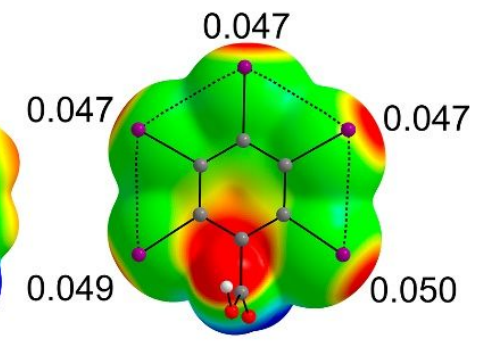

4

$5^{*}$
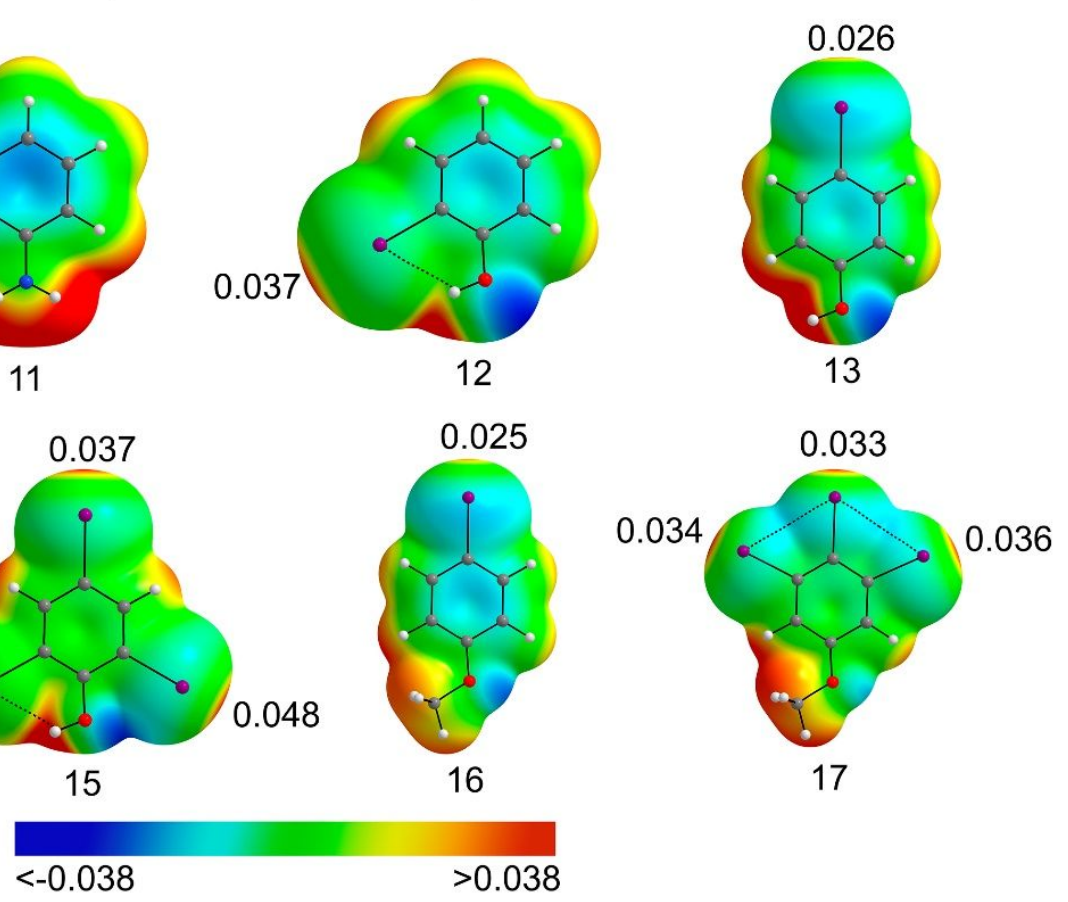

17 
Figure 17. Electrostatic potential calculated at the PBE0-D3/def2TZVP computational level on the 0.001 au molecular surface with the $V_{S, \max }$ values at iodide atoms; same ESP color scale from -0.038 to $0.038 \mathrm{e}^{-1}$ was applied for all of the molecules with a blue color for negative, green for neutral and red for positive values; a color scheme for atoms: H - white, C - gray, O - red, I - purple. *calculations performed for structure omitting the solvent molecule.

\section{CONCLUSIONS}

The conducted structural analysis complemented with the MEP computational analysis show, that the nature of the substituent other than halogen in a benzene ring has an impact on the XB donor and acceptor properties of the iodinated benzenes. The electronwithdrawing substituents, such as $-\mathrm{COOH}$ and $-\mathrm{CN}$, increase the ability of iodines in ortho- or para-positions to act as halogen bond donors. On the other hand, the electron-donating substituents, such as $-\mathrm{OH},-\mathrm{NH}_{2}$ and $-\mathrm{OCH}_{3}$, enhance the $\mathrm{XB}$ donor properties of iodines in meta-position. It is reflected in the size of the o-hole on the iodine atoms, which can be expressed by the value of maximum electrostatic potential ( $\left.V_{\mathrm{S}, \max }\right)$. The stronger the mesomeric effect of the EWG or EDG, the higher impact it makes on the XB donor-acceptor properties of the iodide substituents. Such structural correlations can potentially be exploited in the 
crystal engineering for the design of crystal structures with predefined contacts.

4. EXPERIMENTAL

4.1. Experimental details

3,4,5-triiodobenzoic acid (TIBA) crystals 1 and 2 were obtained by a slow evaporation of an ethanol solvent with an evaporation vessel covered with a parafilm under ambient conditions. TIBA was purchased from Fluka AG, Chemische Fabrik. The isolated yields are $95 \%$ for 1 and 87 o 2. Elemental analysis of 1: found C 16.93 \%, $\mathrm{H} 0.83 \%$, N $0.1 \%$; calculated C $16.8 \%, \mathrm{H} 0.6 \%, \mathrm{~N} 0 \%$ Elemental analysis of 2: found C $19.57 \%$ H $1.554 \%$ N $0.253 \%$; calculated C $19.79 \%, \mathrm{H} 1.65 \%$, 0 \% ${ }^{1} \mathrm{H}$ NMR of 1 (MeOD, $\left.\delta\right): 8.425$ (s, 2H, Ar). ${ }^{1} \mathrm{H}$ NMR of 2 (MeOD, $\left.\delta\right): 1.178$ ( $t, 3 \mathrm{H}, \mathrm{CH} 3$ from ethanol), 3.739 (q, 2H, CH2 from ethanol), 8.425 (s, 2H, Ar). Signal of -COOH proton is too broad to be observable. The obtained crystals of 1 were analyzed with SuperNova Dual X-ray diffractometer using Cu source. Crystals of 2 were analyzed with Bruker KAPPA APEX II CCD X-ray diffractometer. Details on the XRD experiments can be found in ESI .

4.2. Computational details

All of the molecules were subjected to full energy minimization and ESP calculation at DFT level using PBE079-D380 dispersion 
corrected functional with a 6-31G* basis set for all atoms except for iodine, for which a def2-TZVP 81 basis with a pseudopotential for the inner-core electrons was used. Wavefunction files were obtained in Gaussian 09 (revision D.01) program package. ${ }^{82}$ Electrostatic potential of 1-17 was calculated with the QTAIM (Quantum Theory of Atoms in Molecules) ${ }^{83}$ method and visualized in the AIMALL ${ }^{84}$ software by plotting a map of an electrostatic potential (further MEP) at the 0.001 au contour of its electronic density as suggested by Bader et al. ${ }^{85}$

5. ASSOCIATED CONTENT

\section{Supporting Information.}

Details on the XRD experiments and structure determination of 1 and 2, CSD refcodes of 3-17, structural image of 3, hydrogen contacts in $\mathbf{1}$ and $\mathbf{2}$, halogen contacts in $\mathbf{1}, \mathbf{2}, \mathbf{1 1}, \mathbf{1 2 ,} \mathbf{1 4}$ and 15, structures 1-17 with the labels of the atoms, maximum ESP ( $V_{\mathrm{S}, \max }$ ) of the selected halogenated molecules.

\section{Accession Codes}

CCDC 2011890 and 20111891 contain the supplementary crystallographic data for this paper. These data can be obtained free of charge via www.ccdc.cam.ac.uk/data request/cif, or by 
emailing data requesteccdc.cam.ac.uk, or by contacting The Cambridge Crystallographic Data Centre, 12 Union Road, Cambridge CB2 1EZ, UK; fax: +44 1223336033.

6. AUTHOR INFORMATION

\section{Corresponding Author}

*E-mail: (Prof. Dr. Matti Haukka) matti.o.haukka@jyu.fi.

7. REFERENCES

(1) Hassel, O.; Hvoslef, J. The Structure of Bromine 1,4Dioxanate. Acta Chem. Scand. 1954, 5, 873.

(2) Hassel, O. Structural Aspects of Interatomic Charge-Transfer Bonding. Science (80-.). 1970, 170, 497-502.

(3) Dumas, J.-M.; Peurichard, H.; Gomel, M. CX4...base Interactions as Models of Weak Charge-Transfer Interactions: Comparison with Strong Charge-Transfer and Hydrogen-Bond Interactions. J. Chem. Res. 1978, No. 2, 54-57.

(4) Bruckmann, A.; Pena, M. A.; Bolm, C. Organocatalysis through Halogen-Bond Activation. Synlett 2008, No. 6, 900-902. https://doi.org/10.1055/s-2008-1042935.

(5) Sutar, R. L.; Huber, S. M. Catalysis of Organic Reactions through Halogen Bonding. ACS Catal. 2019, 9, 9622-9639. https://doi.org/10.1021/acscatal.9b02894.

(6) Bulfield, D.; Huber, S. M. Halogen Bonding in Organic 
Synthesis and Organocatalysis. Chem. - A Eur. J. 2016, 22, 14434-14450. https://doi.org/10.1002/chem.201601844.

(7) Aakeröy, C. B.; Wijethunga, T. K.; Desper, J. Practical Crystal Engineering Using Halogen Bonding: A Hierarchy Based on Calculated Molecular Electrostatic Potential Surfaces. J. Mol. Struct. 2014, 1072, 20-27.

https://doi.org/10.1016/j.molstruc.2014.02.022.

(8) Ciancaleoni, G. Cooperativity between Hydrogen- and Halogen Bonds: The Case of Selenourea. Phys. Chem. Chem. Phys. 2018, 20,8506-8514. https://doi.org/10.1039/c8cp00353j.

(9) Arman, H. D.; Rafferty, E. R.; Bayse, C. A.; Pennington, W. T. Complementary Selenium••-iodine Halogen Bonding and Phenyl Embraces: Cocrystals of Triphenylphosphine Selenide with Organoiodides. Cryst. Growth Des. 2012, 12, 4315-4323. https://doi.org/10.1021/cg201348u . and Networks. CrystEngComm 2008, 10, 1107-1113. https://doi.org/10.1039/b803329n. Metrangolo, P.; Neukirch, H.; Pilati, T.; Resnati, G. Halogen Bonding Based Recognition Processes: A World Parallel to Hydrogen Bonding. ACC. Chem. Res. 2005, 38, 386395. https://doi.org/10.1021/ar0400995. Metrangolo, P.; Meyer, F.; Pilati, T.; Resnati, G.; Terraneo, G. Halogen Bonding in Supramolecular Chemistry. 
Angew. Chemie - Int. Ed. 2008, 47, 6114-6127.

https://doi.org/10.1002/anie.200800128.

Scholfield, M. R.; Vander Zanden, C. M.; Carter, M.;

Ho, P. S. Halogen Bonding (X-Bonding): A Biological

Perspective. Protein Sci. 2013, 22, 139-152.

https://doi.org/10.1002/pro.2201.

Systems. Biochemistry 2017, 56, 2759-2761.

https://doi.org/10.1021/acs.biochem.7b00371.

Halogen Bonds in Biological Molecules. Proc. Natl. Acad.

SCi.U.S.A. 2004, 101, 16789-16794.

https://doi.org/10.1073/pnas.0407607101.

(16)

Berger, G.; Soubhye, J.; Meyer, F. Halogen Bonding in

Polymer Science: From Crystal Engineering to Functional

Supramolecular Polymers and Materials. Polym. Chem. 2015, 6,

3559-3580. https://doi.org/10.1039/c5py00354g.

(17)

Fourmigué, M.; Batail, P. Activation of Hydrogen- and

Halogen-Bonding Interactions in Tetrathiafulvalene-Based

Crystalline Molecular Conductors. Chem. Rev. 2004, 104,

5379-5418. https://doi.org/10.1021/cr030645s.

(18)

Yamamoto, H. M.; Yamaura, J. I.; Kato, R.

Multicomponent Molecular Conductors with Supramolecular

Assembly: Iodine-Containing Neutral Molecules as Building

ACS Paragon Plus Environment 
Blocks. J. Am. Chem. Soc. 1998, 120, 5905-5913.

https://doi.org/10.1021/ja980024u.

Metrangolo, P.; Präsang, C.; Resnati, G.; Liantonio,

R.; Whitwood, A. C.; Bruce, D. W. Fluorinated Liquid

Crystals Formed by Halogen Bonding. Chem. Commun. 2006, No.

31, 3290-3292. https://doi.org/10.1039/b605101d.

(20)

Xu, J.; Liu, X.; Ng, J. K. P.; Lin, T.; He, C.

Trimeric Supramolecular Liquid Crystals Induced by Halogen

Bonds. J. Mater. Chem. 2006, 16, 3540-3545.

https://doi.org/10.1039/b606617h.

(21)

Nguyen, H. L.; Horton, P. N.; Hursthouse, M. B.;

Legon, A. C.; Bruce, D. W. Halogen Bonding: A New

Interaction for Liquid Crystal Formation. J. Am. Chem. Soc.

2004, 126, 16-17. https://doi.org/10.1021/ja0369941.

(22)

Metrangolo, P.; Pilati, T.; Resnati, G. Halogen

Bonding and Other Noncovalent Interactions Involving

Halogens: A Terminology Issue. CrystEngComm 2006, 8, 946 -

947. https://doi.org/10.1039/b610454a.

(23)

Wilcken, R.; Zimmermann, M. O.; Lange, A.; Joerger, A.

C.; Boeckler, F. M. Principles and Applications of Halogen

Bonding in Medicinal Chemistry and Chemical Biology. J. Med.

Chem. 2013, 56, 1363-1388.

https://doi.org/10.1021/jm3012068.

Cavallo, G.; Metrangolo, P.; Milani, R.; Pilati, T.; 
Primagi, A.; Resnati, G.; Terraneo, G. The Halogen Bond. Chem. Rev. 2016, 116, 2478-2601.

https://doi.org/10.1021/acs.chemrev.5b00484. Clark, T.; Hennemann, M.; Murray, J. S.; Politzer, P. Halogen Bonding: The o-Hole. J. Mol. Model. 2007, 13, 291296. https://doi.org/10.1007/s00894-006-0130-2. Metrangolo, P.; Resnati, G. Type II Halogen..halogen Contacts Are Halogen Bonds. IUCrJ 2014, 1, 5-7. https://doi.org/10.1107/S205225251303491X.

Marquardt, R.; Metrangolo, P.; Politzer, P.; Resnati, G.; Rissanen, K. Definition of the Halogen Bond (IUPAC Recommendations 2013). Pure Appl. Chem. 2013, 85, 1711-1713. https://doi.org/10.1351/PAC-REC-12-05-10. Substitution; 2018. https://doi.org/10.1016/b978-0-12$812838-1.50013-x$ Pramanik, S.; Dey, T.; Mukherjee, A. K. Five Benzoic Acid Derivatives: Crystallographic Study Using X-Ray Powder Diffraction, Electronic Structure and Molecular Electrostatic Potential Calculation. J. Mol. Struct. 2019, $1175,185-194$

https://doi.org/10.1016/j.molstruc.2018.07.090. Allen, F. H.; Satish Goud, B.; Hoy, V. J.; Howard, J. 
A. K.; Desiraju, G. R. Molecular Recognition via Iodo--Nitro and Iodo---Cyano Interactions: Crystal Structures of the 1:1 Complexes of 1,4-Diiodobenzene with 1,4Dinitrobenzene and 7,7,8,8-Tetracyanodimethane (TCNQ). J. Chem. Soc. Chem. Commun. 1994, 2729-2730. https://doi.org/10.1002/(SICI) 1099$1409(200006 / 07) 4: 4<393::$ AID-JPP227>3.3.CO;2-2.

Crystallogr. Sect. E Struct. Reports Online 2007, 63, 20062007. https://doi.org/10.1107/S1600536806054535. Nygren, C. L.; Wilson, C. C.; Turner, J. F. C. On the Solid State Structure of 4-Iodobenzoic Acid. J. Phys. Chem. A 2005, 109, 2586-2593. https://doi.org/10.1021/jp047189b. Adonin, S. A.; Bondarenko, M. A.; Novikov, A. S.;

Abramov, P. A.; Sokolov, M. N.; Fedin, V. P. Halogen Bonding in the Structures of Pentaiodobenzoic Acid and Its Salts. CrystengComm 2019, 21, 6666-6670. https://doi.org/10.1039/c9ce01106d. Steer, R. J.; Watkins, S. F.; Woodward, P. Crystal and Molecular Structure of Hexaiodobenzene. J. Chem. Soc. 1970, 403-408. https://doi.org/10.1017/CB09781107415324.004. Ghosh, S.; Reddy, C. M.; Desiraju, G. R.

Hexaiodobenzene: A Redetermination at 100 K. Acta Crystallogr. Sect. E Struct. Reports Online 2007, 63, 910- 
911. https://doi.org/10.1107/S1600536807002279.

(36) Giordano, N.; Afanasjevs, S.; Beavers, C. M.; Hobday,

C. L.; Kamenev, K. V.; O'Bannon, E. F.; Ruiz-Fuertes, J.;

Teat, S. J.; Valiente, R.; Parsons, S. The Effect of

Pressure on Halogen Bonding in 4-Iodobenzonitrile. Molecules

2019, 24, 1-23. https://doi.org/10.3390/molecules24102018.

Merz, K. Substitution Effect on Crystal Packings of

Iodobenzonitriles and Iodophenols. Cryst. Growth Des. 2006,

$6,1615-1619$

(38)

Smith, G.; Wermuth, U. D. 2,4-Diiodoaniline. Acta

Crystallogr. Sect. E Struct. Reports Online 2009, 65, 2018.

https://doi.org/10.1107/S1600536809030438.

(39)

Dey, A.; Jetti, R. K. R.; Boese, R.; Desiraju, G. R.

Supramolecular Equivalence of Halogen, Ethynyl and Hydroxy

Groups. A Comparison of the Crystal Structures of Some 4-

Substituted Anilines. CrystEngComm 2003, 5, 248-252.

https://doi.org/10.1039/b304785g .

$(40)$

Parkin, A.; Spanswick, C. K.; Pulham, C. R.; Wilson,

C. C. 2-Iodoaniline at 100 K. Acta Crystallogr. Sect. E

Struct. Reports Online 2005, 61, 1087-1089.

https://doi.org/10.1107/S1600536805007038.

(41)

Prout, K.; Fail, J.; Jones, R. M.; Warner, R. E.;

Emmett, J. C. A Study of the Crystal and Molecular

Structures of Phenols with Only Intermolecular Hydrogen

ACS Paragon Plus Environment 
Bonding. J. Chem. Soc. Perkin Trans. 2 1988, No. 3, 265-284. https://doi.org/10.1039/P29880000265.

Nath, N. K.; Saha, B. K.; Nangia, A. Isostructural

Polymorphs of Triiodophloroglucinol and Triiodoresorcinol.

New J. Chem. 2008, 32, 1693-1701.

https://doi.org/10.1039/b804905j.

Structure Determination of a Series of Small Organic

Compounds from Powder Data. Zeitschrift fur Krist. 2001, 216, 176-181. https://doi.org/10.1524/zkri.216.3.176.20326. Al-Zoubi, R. M.; Al-Mughaid, H.; Al-Zoubi, M. A.;

Jaradat, K. T.; McDonald, R. Facile, One-Pot, and Gram-Scale Synthesis of 3,4,5-Triiodoanisole through a $\mathrm{C}-\mathrm{H}$ Iodination/Ipso-Iododecarboxylation Strategy: Potential Application towards 3,4,5-Trisubstituted Anisoles. European J. Org. Chem. 2015, 2015, 5501-5508.

https://doi.org/10.1002/ejoc.201500887. Elhiti, M.; Stasolla, C. Ectopic Expression of the Brassica SHOOTMERISTEMLESS Attenuates the Deleterious Effects of the Auxin Transport Inhibitor TIBA on Somatic Embryo Number and Morphology. Plant SCi. 2011, 180, 383-390. https://doi.org/10.1016/j.plantsci.2010.10.014. Miyamoto, K.; Inui, A.; Uheda, E.; Oka, M.; Kamada, M.; Yamazaki, C.; Shimazu, T.; Kasahara, H.; Sano, H.; 
Suzuki, T.; Higashibata, A.; Ueda, J. Polar Auxin Transport Is Essential to Maintain Growth and Development of Etiolated Pea and Maize Seedlings Grown under $1 \mathrm{~g}$ Conditions: Relevance to the International space Station Experiment. Life Sci. Sp. Res. 2019, 20, 1-11.

https://doi.org/10.1016/j.1ssr.2018.11.001. Zhang, L.; Yan, P.; Shen, C.; Zhang, L.; Wei, J.; Xu, H.; Li, X.; Han, W. Effects of Exogenous TIBA on Dwarfing, Shoot Branching and Yield of Tea Plant (Camellia Sinensis L.). Sci. Hortic. (Amsterdam). 2017, 225, 676-680. https://doi.org/10.1016/j.scienta.2017.07.060. Ice, R. D.; Christian, J. E.; Plumlee, M. P. Metabolic Fate of Orally Administered 2,3,5-triiodobenzoic Acid in Lactating Animals. J. Pharm. Sci. 1968, 57, 399-404. https://doi.org/10.1002/jps.2600570306.

J. Metabolites of 2,3,5-Triiodobenzoic Acid in Cow's Milk. J. Dairy SCi. 1969, 52, 1864-1866.

https://doi.org/10.3168/jds.s0022-0302 (69)86858-X. Li, Y.; Zhang, Z.; Wu, Q. Isolation and Expression Analysis of the Ethylene Receptor Gene MiETRlb in Mango (Mangifera Indica). Hortic. Plant J. 2016, 2, 1-8. https://doi.org/10.1016/j.hpj.2016.02.008. Gerritse, J.; Gottschal, J. C. Mineralization of the 
Herbicide 2,3,6-trichlorobenzoic Acid by a Co-culture of Anaerobic and Aerobic Bacteria. FEMS Microbiol. Lett. 1992, 101, 89-98. https://doi.org/10.1111/j.15746968.1992.tb05765.x.

(52) Gichner, T.; Lovecka, P.; Vrchotova, B. Genomic Damage Induced in Tobacco Plants by Chlorobenzoic Acids-Metabolic Products of Polychlorinated Biphenyls. Mutat. Res. - Genet. Toxicol. Environ. Mutagen. 2008, 657, 140-145. https://doi.org/10.1016/j.mrgentox.2008.08.021. McDowell, R. W.; Landolt, R. R.; Kessler, W. V.; Shaw, S. M. Placental Transfer of 2, 3, 5-triiodobenzoic Acid in the Rat. J. Pharm. Sci. 1971, 60, 695-699. https://doi.org/10.1002/jps.2600600507. Ali, A. H. N.; Jarvis, B. C. Effects of 2,3,5Triiodobenzoic Acid on the Regeneration of Callus and Adventitious Roots on Stem Cuttings of Mung Bean, Phaseolus Aureus ROXB. Biochem. und Physiol. der Pflanz. 1988, 183, 509-513. https://doi.org/10.1016/s0015-3796(88)80013-1. Abdelgadir, H. A.; Jäger, A. K.; Johnson, S. D.; Van Staden, J. Influence of Plant Growth Regulators on Flowering, Fruiting, Seed Oil Content, and Oil Quality of Jatropha Curcas. South African J. Bot. 2010, 76, 440-446. https://doi.org/10.1016/j.sajb.2010.02.088. Safa, A. R.; Tseng, M. T.; Ballou, R. J. Influence of 
a Plant Growth Regulator (2,3,5-Triiodobenzoic Acid) on Cultured Mammary Tumor Cells. 69621. Andrejauskas, E.; Hertel, R.; Marmé, D. 3,4,5Triiodobenzoic Acid Affects [3H]Verapamil Binding to Plant and Animal Membrane Fractions and Smooth Muscle Contraction. Biochem. Biophys. Res. Commun. 1986, 138, 1269-1275. Šebánek, J.; Jandáková, B. The Effect of Jasmonic and 2, 3, 5-Triiodobenzoic Acid on the Correlation between Cotyledons and Their Axillary Buds in Flax Linum Usitatissimum and Pea Pisum Sativum Seedlings. Biochem. und Physiol. der Pflanz. 1984, 179, 351-357. https://doi.org/10.1016/s0015-3796(84)80011-6. Beck, C.; Jensen, S. B.; Reglinski, J. The Selenium Mediated De-Iodination of Iodophenols: A Model for the Mechanism of 5' Thyronine de-Iodinase. Bioorganic Med. Chem. Lett.1994, 4, 1353-1356. https://doi.org/10.1016/s0960$894 X(01) 80360-7$

$$
\text { Kadar, M.; Nagy, Z.; Karancsi, T.; Farsang, G. The }
$$
Electrochemical Oxidation of 4-Bromoaniline, 2,4Dibromoaniline, 2,4,6-Tribromoaniline and 4-Iodoaniline in Acetonitrile Solution. Electrochim. Acta 2001, 46, 34053414

Bianco Prevot, A.; Pramauro, E. Analytical Monitoring of Photocatalytic Treatments. Degradation of 2,3,6- 
Trichlorobenzoic Acid in Aqueous TiO2 Dispersions. Talanta 1999, 48, 847-857. https://doi.org/10.1016/S0039$9140(98) 00101-5$.

$$
\text { Balavoine, F.; Madec, D.; Mioskowski, C. Highly }
$$

Regioselective Palladium-Catalyzed Condensation of Terminal Acetylenes with 2,5-Diiodobenzoic Acid. Tetrahedron Lett. 1999, 40, 8351-8354. https://doi.org/10.1016/S00404039 (99) $01697-4$.

$$
\text { Wang, R.; Ding, Y. L.; Liu, H.; Peng, S.; Ren, J.; Li, }
$$

L. Copper-Catalyzed Multicomponent Reactions of 2-

Iodoanilines, Benzylamines, and Elemental sulfur toward 2Arylbenzothiazoles. Tetrahedron Lett. 2014, 55, 945-949. https://doi.org/10.1016/j.tetlet.2013.12.054. Ács, P.; Müller, E.; Rangits, G.; Lóránd, T.; Kollár,

L. Palladium-Catalysed Carbonylation of 4-Substituted 2Iodoaniline Derivatives: Carbonylative Cyclisation and Aminocarbonylation. Tetrahedron 2006, 62, 12051-12056. https://doi.org/10.1016/j.tet.2006.09.076. Yao, F.; Hao, W.; Cai, M. Z. Copper(I)-Catalyzed

Tandem Reaction of 2-Iodophenols with Isothiocyanates in Room Temperature Ionic Liquids. J. Organomet. Chem. 2013, $723,137-142$.

https://doi.org/10.1016/j.jorganchem.2012.09.010.

$$
\text { Rao, M. L. N.; Meka, S. Pd-Catalyzed Protecting-Group- }
$$


Free Cross-Couplings of Iodophenols with Atom-Economic Triarylbismuth Reagents. Tetrahedron Lett. 2020, 61, 151512. https://doi.org/10.1016/j.tetlet.2019.151512. (67) Wang, Y.; Wang, M.; Han, L.; Zhao, Y.; Fan, A. Enhancement Effect of P-Iodophenol on Gold NanoparticleCatalyzed Chemiluminescence and Its Applications in Detection of Thiols and Guanidine. Talanta 2018, 182, 523528. https://doi.org/10.1016/j.talanta.2018.01.093. Keshavarz, M. H.; Gharagheizi, F.; Shokrolahi, A.;

Zakinejad, S. Accurate Prediction of the Toxicity of Benzoic Acid Compounds in Mice via Oral without Using Any Computer Codes. J. Hazard. Mater. 2012, 237-238, 79-101. https://doi.org/10.1016/j.jhazmat.2012.07.048. El-Athman, F.; Jekel, M.; Putschew, A. Reaction Kinetics of Corrinoid-Mediated Deiodination of Iodinated XRay Contrast Media and Other Iodinated Organic Compounds. Chemosphere 2019, 234, 971-977.

https://doi.org/10.1016/j.chemosphere.2019.06.135. Xi, Y.; Yang, X.; Zhang, H.; Liu, H.; Watson, P.; Yang, F. Binding Interactions of Halo-Benzoic Acids, HaloBenzenesulfonic Acids and Halo-Phenylboronic Acids with Human Transthyretin. Chemosphere 2020, 242, 125135. https://doi.org/10.1016/j.chemosphere.2019.125135. Muzikář, M.; Křesinová, Z.; Svobodová, K.; Filipová, 
A.; Čvančarová, M.; Cajthamlová, K.; Cajthaml, T. Biodegradation of Chlorobenzoic Acids by Ligninolytic Fungi. J. Hazard. Mater. 2011, 196, 386-394.

https://doi.org/10.1016/j.jhazmat.2011.09.041.

Zhang, Y.; Zheng, J. M. Three Ln (III)-2,3,5-

Trichlorobenzoate Coordination Polymers ( $\mathrm{Ln}=\mathrm{Tb}$, Ho and

Er): Syntheses, Structures and Magnetic Properties. Inorg.

Chem. Commun. 2015, 59, 21-24.

https://doi.org/10.1016/j.inoche.2015.06.018.

(73)

Mantina, M.; Chamberlin, A. C.; Valero, R.; Cramer, C.

J.; Truhlar, D. G. Consistent van Der Waals Radü for the

Whole Main Group. J. Phys. Chem. A 2009, 113, 5806-5812.

https://doi.org/10.1021/jp8111556.

( 74$)$

Politzer, P.; Murray, J. S.; Clark, T. Halogen Bonding

and Other o-Hole Interactions: A Perspective. Phys. Chem.

Chem. Phys. 2013, 15, 11178-11189.

https://doi.org/10.1039/c3cp00054k.

(75) Perera, M. D.; Desper, J.; Sinha, A. S.; Aakeröy, C.

B. Impact and Importance of Electrostatic Potential

Calculations for Predicting Structural Patterns of Hydrogen

and Halogen Bonding. CrystEngComm 2016, 18, 8631-8636.

https://doi.org/10.1039/c6ce02089e.

(76)

Kolář, M.; Hostaš, J.; Hobza, P. The Strength and

Directionality of a Halogen Bond Are Co-Determined by the

ACS Paragon Plus Environment 
Magnitude and Size of the o-Hole. Phys. Chem. Chem. Phys. 2014, 16, 9987-9996. https://doi.org/10.1039/c3cp55188a. Clark, T.; Hennemann, M.; Murray, J. S.; Politzer, P. Halogen Bonding: The o-Hole. J. Mol. Model. 2007, 13, 291296. https://doi.org/10.1007/s00894-006-0130-2.

Anion Recognition. Chem 2018, 4, 731-783.

https://doi.org/https://doi.org/10.1016/j.chempr.2018.02.022

(79) Adamo, C.; Barone, V. Toward Reliable Density

Functional Methods without Adjustable Parameters: The PBE0 Model. J. Chem. Phys. 1999, 110, 6158-6170. https://doi.org/10.1063/1.478522. Steinmetz, M.; Grimme, S. Benchmark Study of the Performance of Density Functional Theory for Bond Activations with (Ni, $\mathrm{Pd})$-Based Transition-Metal Catalysts. Chemistryopen 2013, 2, 115-124. https://doi.org/10.1002/open.201300012. Contracted Gaussian Basis Sets of Triple Zeta Valence Quality for Atoms Li to Kr. J. Chem. Phys. 1994, 100, 58295835. https://doi.org/10.1063/1.467146.

$$
\text { Frisch, M. J.; Trucks, G. W.; Schlegel, H. B.; }
$$

Scuseria, G. E.; Robb, M. A.; Cheeseman, J. R.; Scalmani, 
G.; Barone, V.; Mennucci, B.; Petersson, G. A.; Nakatsuji, H.; Caricato, M.; Li, X.; Hratchian, H. P.; Izmaylov, A. F.; Bloino, J.; Zheng, G.; Sonnenb, J.; Fox, D. J. Gaussian 09, Revision C.01; Gaussian, Inc., Wallingford CT, 2009. Bader, R. F. W. Atoms in Molecules: A Quantum Theory; Clarendon Press: Oxford, 1990. Software, Overland Park KS, USA, 2012 (aim.tkgristmill.com). Bader, R. F. W.; Carroll, M. T.; Cheeseman, J. R.; Chang, C. Properties of Atoms in Molecules: Atomic Volumes. J. Am. Chem. Soc. 1987, 109, 7968-7979. https://doi.org/10.1021/ja00260a006.

For Table of Contents Use Only

Manuscript title: Influence of substituents in aromatic ring on the strength of halogen bonding in iodobenzene derivatives 
Author list: Maria V. Chernysheva, Margarita Bulatova, Xin Ding, Matti Haukka*

\section{TOC graphic:}

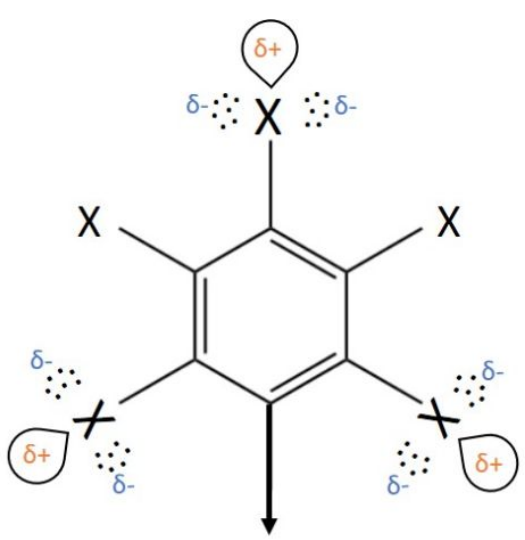

A

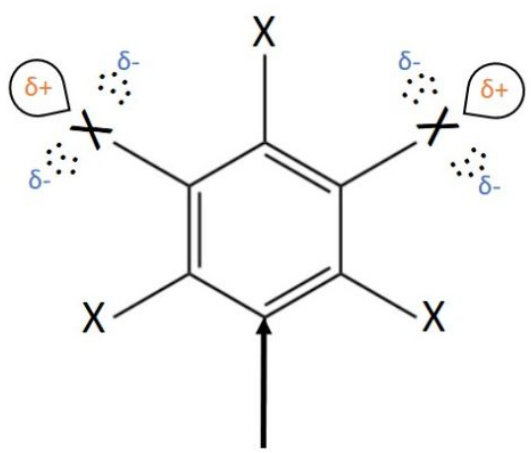

D

where $\mathrm{X}=\mathrm{I}$ or $\mathrm{H}, \mathrm{A}$ = electron acceptor $(-\mathrm{COOH},-\mathrm{CN}), \mathrm{D}=$ electron donor $\left(-\mathrm{OH},-\mathrm{NH}_{2},-\mathrm{OCH}_{3}\right)$

\section{Synopsis :}

Structural and computational MEP analyses of 3,4,5-triiodobenzoic acid (1, 2), 1,2,3-triiodobenzene (3), 4-iodobenzoic acid (4), pentaiodobenzoic acid ethanol solvate (5), hexaiodobenzene (6a, 
6b, 6c), 4-iodobenzonitrile (7), 3-iodobenzonitrile (8), 2,4diiodoaniline (9), 4-iodoaniline (10), 2-iodoaniline (11), 2iodophenol (12), 4-iodophenol (13), 3-iodophenol (14), 2,4,6triiodophenol (15), 4-iodoanisole (16), 3,4,5-triiodoanisole (17) have been conducted. The results show that the mesomeric effect of the substituents other than halogen in the benzene ring has an impact on the XB donor-acceptor properties of the iodide substituents in ortho-, meta- and para-positions. Thus, electronwithdrawing (EWG) substituents with negative mesomeric effect, e.g. carboxyl - $\mathrm{COOH}$ and nitrile -CN, favor iodines in ortho- and para-positions to act as halogen bond donors. On the other hand, electron-donating (EDG) substituents, like amino - $\mathrm{NH}_{2}$, hydroxy $\mathrm{OH}$ and methoxy $-\mathrm{OCH}_{3}$ groups, which reveal positive mesomeric effect, increase the ability of meta-iodines to act as halogen bond donors. Furthermore, EWG and EDG substituents with stronger mesomeric effect make a higher impact on the XB donor ability of the iodide substituents. Such correlation is reflected in the size of the o-hole on the iodine atoms. Thus, the sigma-holes on o- and p-iodine atoms are bigger than on m-iodine atoms in the presence of EWG, making $o^{-}$and p-iodines favorable XB donors. Similarly, the size of the sigma-hole on m-iodines is being larger than the ones on the $o^{-}$and p-iodines in the presence of EDG, making miodines to favor XB donor behavior. This is confirmed by our MEP calculations, in which the size of the o-hole is expressed by the 


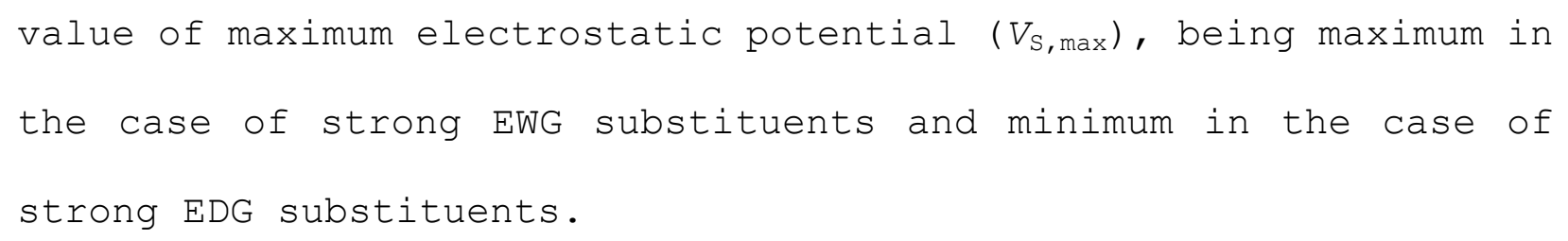

